\title{
Expansion and systematics redefinition of the most threatened freshwater mussel family, the Margaritiferidae
}

Manuel Lopes-Lima ${ }^{\mathrm{a}, \mathrm{b}, \mathrm{c}, *}$, Ivan N. Bolotov ${ }^{\mathrm{d}, \mathrm{e}}$, Van Tu Do ${ }^{\mathrm{f}}$, David C. Aldridge ${ }^{g}$, Miguel M. Fonseca ${ }^{\mathrm{b}}$, Han Ming Gan ${ }^{\mathrm{h}}$, Mikhail Y. Gofarov ${ }^{\mathrm{d}, \mathrm{e}}$, Alexander V. Kondakov ${ }^{\mathrm{d}, \mathrm{e}}$, Vincent Prié ${ }^{\mathrm{i}}$, Ronaldo Sousa ${ }^{\mathrm{b}, \mathrm{j}}$, Simone Varandas ${ }^{\mathrm{k}}$, Ilya V. Vikhrev ${ }^{\mathrm{d}, \mathrm{e}}$, Amílcar Teixeira ${ }^{\mathrm{l}}$, Rui-Wen $\mathrm{Wu}^{\mathrm{m}}$, Xiaoping $\mathrm{Wu}^{\mathrm{m}}$, Alexandra Zieritz ${ }^{\mathrm{n}}$, Elsa Froufe ${ }^{\mathrm{b}}$, Arthur E. Bogan ${ }^{\mathrm{o}}$

${ }^{\text {a } C I B I O / I n B I O}$ - Research Center in Biodiversity and Genetic Resources, University of Porto, Campus Agrário de Vairão, Rua Padre Armando Quintas 7, 4485-661 Vairão, Portugal

b CIIMAR/CIMAR - Interdisciplinary Centre of Marine and Environmental Research, University of Porto, Terminal de Cruzeiros do Porto de Leixões, Avenida General Norton de Matos S/N, 4450-208 Matosinhos, Portugal

${ }^{\mathrm{c}}$ SSC/IUCN - Mollusc Specialist Group, Species Survival Commission, International Union for Conservation of Nature, c/o The David Attenborough Building, Pembroke Street, CB2 3QZ Cambridge, United Kingdom

d IBIGER - Institute of Biogeography and Genetic Resources, Federal Center for Integrated Arctic Research, Russian Academy of Sciences, Severnaya Dvina Emb. 23, 163000 Arkhangelsk, Russian Federation

e Northern Arctic Federal University, Severnaya Dvina Emb. 17, 163000 Arkhangelsk, Russian Federation

${ }_{\mathrm{f}}$ Department of Aquatic Ecology and Water Environment, Institute of Ecology and Biological Resources, Vietnam Academy of Science and Technology, 18 Hoang Quoc Viet, Cau Giay, Ha Noi, Viet Nam

${ }^{g}$ Department of Zoology, University of Cambridge, The David Attenborough Building, Pembroke Street, Cambridge CB2 3QY, United Kingdom

${ }^{\text {h }}$ Centre for Integrative Ecology, School of Life and Environmental Sciences, Deakin University, Geelong, 3220 Victoria, Australia

${ }^{\mathrm{i}}$ Institut de Systématique, Évolution, Biodiversité ISYEB - UMR 7205 - CNRS, MNHN, UPMC, EPHE, Muséum national d'Histoire naturelle, Sorbonne Universités, 57 rue Cuvier, CP26, F-75005 Paris, France

${ }^{\mathrm{j}}$ CBMA - Centre of Molecular and Environmental Biology, Department of Biology, University of Minho, Campus Gualtar, 4710-057 Braga, Portugal

${ }^{\mathrm{k}}$ CITAB/UTAD - Centre for Research and Technology of Agro-Environment and Biological Sciences, University of Trás-os-Montes and Alto Douro, Forestry Department, 5000-801 Vila Real, Portugal

${ }^{1}$ CIMO-ESA-IPB - Mountain Research Centre, School of Agriculture, Polytechnic Institute of Bragança, Campus de Santa Apolónia, 5301-854 Bragança, Portugal

${ }^{\mathrm{m}}$ School of Life Sciences, Center for Watershed Ecology, Institute of Life Science, Nanchang University, Nanchang 330031, People's Republic of China

${ }^{\mathrm{n}}$ School of Environmental and Geographical Sciences, University of Nottingham Malaysia Campus, Jalan Broga, 43500 Semenyih, Malaysia

${ }^{\circ}$ Research Laboratory, North Carolina State Museum of Natural Sciences, MSC 1626, Raleigh, NC 27699-1626, United States

\section{A R T I C L E I N F O}

\section{Keywords:}

Unionida

Margaritifera

Lamprotula

Gibbosula

Phylogeny

Bivalvia

\begin{abstract}
A B S T R A C T
Two Unionida (freshwater mussel) families are present in the Northern Hemisphere; the Margaritiferidae, representing the most threatened of unionid families, and the Unionidae, which include several genera of unresolved taxonomic placement. The recent reassignment of the poorly studied Lamprotula rochechouartii from the Unionidae to the Margaritiferidae motivated a new search for other potential species of margaritiferids from members of Gibbosula and Lamprotula. Based on molecular and morphological analyses conducted on newly collected specimens from Vietnam, we here assign Gibbosula crassa to the Margaritiferidae. Additionally, we reanalyzed all diagnostic characteristics of the Margaritiferidae and examined museum specimens of Lamprotula and Gibbosula. As a result, two additional species are also moved to the Margaritiferidae, i.e. Gibbosula confragosa and Gibbosula polysticta. We performed a robust five marker phylogeny with all available margaritiferid species and discuss the taxonomy within the family. The present phylogeny reveals the division of Margaritiferidae into four ancient clades with distinct morphological, biogeographical and ecological characteristics that justify the division of the Margaritiferidae into two subfamilies (Gibbosulinae and Margaritiferinae) and four genera (Gibbosula, Cumberlandia, Margaritifera, and Pseudunio). The systematics of the Margaritiferidae family is redefined as well as their distribution, potential origin and main biogeographic patterns.
\end{abstract}

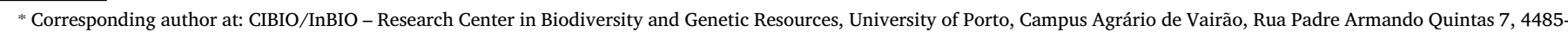
661 Vairão, Portugal.

E-mail address: manuelpmlopeslima@gmail.com (M. Lopes-Lima). 


\section{Introduction}

\subsection{Unionida freshwater mussels: diversity and conservation status}

The Unionida is the only strictly freshwater order of bivalves (Bogan, 2008). It is an old and widespread order with approximately 800 described species in 180 genera (Bogan, 2008). Six families are currently recognized within Unionida, but only the Unionidae and the Margaritiferidae are widespread in the Northern Hemisphere (Bogan, 2008). While the Unionidae is extremely diverse ( $>600$ species), until the present study, only 12 species in one genus scattered across North America, Europe, North Africa and Asia had been recognized within the Margaritiferidae (Bolotov et al., 2016; Araujo et al., 2017). Additionally, both families are declining globally and are highly endangered, especially the Margaritiferidae, where all species assessed with sufficient data present a near threatened or threatened conservation status (IUCN, 2018).

\subsection{Taxonomical history of the Margaritiferidae and its diagnostic characters}

Until the end of the twentieth century, the taxonomy and systematics of Unionida had been based primarily on conchological and anatomical characters (e.g. Haas, 1969a; Parmalee and Bogan, 1998; Watters et al., 2009). Due to the better availability of Unionida specimens from North America and Europe, those from tropical and the Southern Hemisphere regions were relatively poorly studied (Simpson, 1900, 1914; Ortmann, 1921; McMichael and Hiscock, 1958).

Early systematists encompassed all genera of freshwater mussels, including Margaritana (=Margaritifera) species, within the family Unionidae (Table 1: Lea, 1836, 1838, 1852, 1870; Simpson, 1900, 1914; Frierson, 1927). However, in the beginning of the twentieth century, Ortmann (1910) determined that some anatomical characters of some genera were distinct and of prime systematic value. This author erected a new taxon, first as a sub-family, Margaritaninae within Unionidae, but immediately after as a separate family, the Margaritanidae (=Margaritiferidae Henderson, 1929, (1910)), both with the genus and species Margaritana (=Margaritifera) margaritifera (Linnaeus, 1758) as the type. As defined by Ortmann (1910, 1911a,b, 1912), the Margaritanidae presented distinct anatomical features from the other Unionidae species, including the lack of discrete apertures separated by mantle fusions, particular gill and marsupium structure, and glochidial (larval) shape (Table 2). Although at first other malacologists did not recognize Margaritiferidae as a separate family (e.g., Simpson, 1914), soon it was accepted by most researchers (e.g. Henderson, 1929), including in the comprehensive classification of the Unionida published by Haas (1969a,b). In this fundamental work, the family Margaritiferidae was recognized with nine taxa (five species and four subspecies) under a single genus, Margaritifera, divided in four subgenera: Margaritifera, Cumberlandia, Margaritanopsis and Pseudunio.

During the same period, alternative classifications were published (Modell, 1942, 1949, 1964; Starobogatov, 1970, 1995; Bogatov et al., 2003) based only on few conchological characters that proposed a much larger number of taxa in the Margaritiferidae (Table 1). These studies were controversial and subsequently ignored by most malacologists (e.g., Boss, 1982; Smith, 2001, Graf and Cummings, 2007). Since the beginning of this century, the family Margaritiferidae has been consistently restricted to around 12 species (Smith, 2001; Huff et al., 2004; Graf and Cummings, 2006). Smith (2001), based on morphological characters only, divided the Margaritiferidae into three genera: Pseudunio, Margaritifera, and Margaritanopsis. Soon after, a molecular phylogenetic analysis was published using both nuclear and mitochondrial markers on seven Margaritiferidae species (Huff et al., 2004). Although these phylogenetic analyses presented three clear clades, these did not agree with the genera previously defined by Smith (2001), causing Huff et al. (2004) to conclude that the generic name
Margaritifera should be considered for all species. In subsequent phylogenetic studies, the Margaritiferidae has been presented consistently as monophyletic, with a marked genetic structure and divided into three to four major clades; however, most authors have chosen not to discuss its generic assignment keeping Margaritifera as the single genus (Huff et al., 2004; Graf and Cummings, 2007; Araujo et al., 2017). Nevertheless, many North American researchers continued to recognize Cumberlandia as a valid genus (e.g. Watters et al., 2009; Haag, 2012).

Recently, two comprehensive five loci molecular phylogenies on the Margaritiferidae documented several well-supported divergent clades. Bolotov et al. (2016) recognized only three main clades, assigning them as subgenera (Margaritanopsis, Margaritifera, and Pseudunio) of Margaritifera, resembling the previous classification by Haas (1969a). Shortly afterwards, Araujo et al. (2017) described five major divergent clades within the Margaritiferidae, but kept them under the same genus (Margaritifera).

\subsection{Biogeography and diversification of the Margaritiferidae}

The family Margaritiferidae has a broad but disjunct distribution range in the Northern Hemisphere (Smith, 2001). It presents an enigmatic biogeographic pattern with species aggregations along the western and eastern continental margins and vast distribution gaps in inland areas (e.g., East Europe, Urals and Siberia), possibly reflecting vicariance events driven by plate tectonics (Taylor, 1988; Smith, 2001; Huff et al., 2004). Recently, Bolotov et al. (2016) and Araujo et al. (2017) reviewed available biogeographic schemes explaining the origin and expansion routes of the Margaritiferidae and independently provided new fossil-calibrated evolutionary models. However, the time and place of origin of the entire family remained unclear (Bolotov et al., 2016; Araujo et al., 2017). The phylogenetic models placed the origin of the Margaritiferidae in the mid-Cretaceous (Bolotov et al., 2016) or even in the Late Triassic (Araujo et al., 2017). The strong temporal discordance between these fossil-calibrated phylogenies together with significant topological differences and low support values in several deep nodes suggest that both studies need additional taxon samples. Inclusion of Pseudunio homsensis from the Orontes River in Turkey, that had been missing from the previous phylogenetic studies (Bolotov et al., 2016; Araujo et al., 2017), did not help to obtain a fully resolved evolutionary reconstruction for the family, as it appears to be a close relative of $P$. auricularius (Vikhrev et al., 2017). Additionally, previous analyses also lacked Margaritiferidae taxa from eastern China (i.e., between the Indo-China Peninsula and the Amur River; Smith, 2001; Bolotov et al., 2015, 2016). As has already been noted (Smith, 2001; Bolotov et al., 2015), inclusion of newly discovered species from this vast range disjunction is crucial for developing a comprehensive understanding of the biogeography of the Margaritiferidae. Huang et al. (2017) added molecular sequences of Gibbosula rochechouartii to the data set of Araujo et al. (2017) and calculated an updated fossil-calibrated phylogeny placing the origin of the Margaritiferidae crown group in the Late Cretaceous but were not able to obtain a well-resolved biogeographic reconstruction.

A large number of fossil specimens assigned to the Margaritiferidae has been recovered in Europe, Middle Asia, China, Mongolia, Siberia, Japan, North America, and Africa (e.g., Henderson, 1935; Modell, 1957; Martinson, 1982; Ma, 1996; Fang et al., 2009; Van Damme et al., 2015; Bolotov et al., 2016; Araujo et al., 2017). However, recent phylogenetic models were calculated using a limited set of fossil calibrations because the true phylogenetic affinities of many fossil taxa remain unclear due to high conchological variability (Bolotov et al., 2016; Araujo et al., 2017; Huang et al., 2017). The high taxonomic diversity of fossil margaritiferids disagrees with the limited number of extant taxa and likely reflects a lack of critical revisions in systematic paleontology rather than multiple extinction events (Schneider and Prieto, 2011; Bolotov et al., 2016; Araujo et al., 2017). Slow substitution rates in the Margaritiferidae (Bolotov et al., 2016) allow us to expect rather 


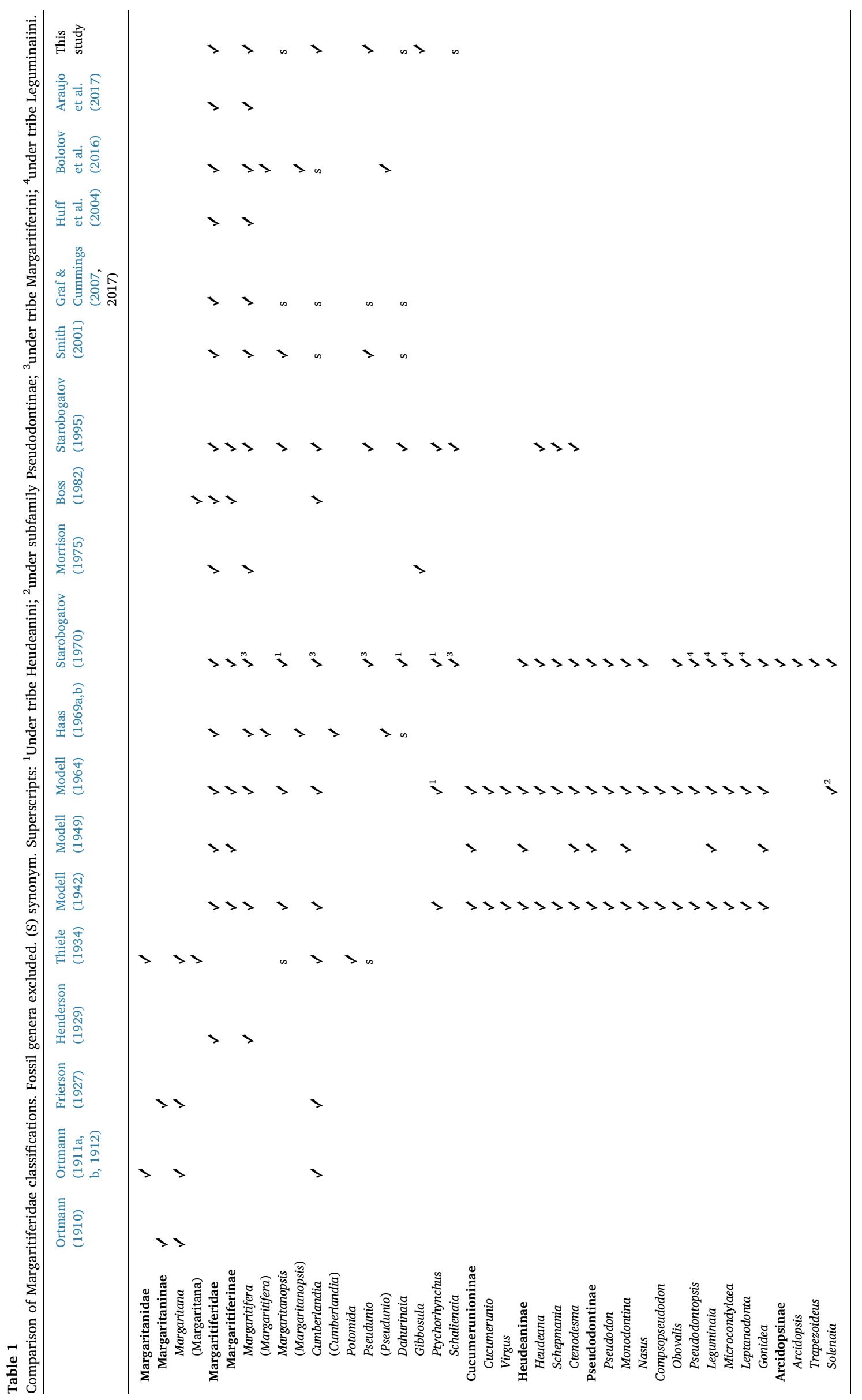




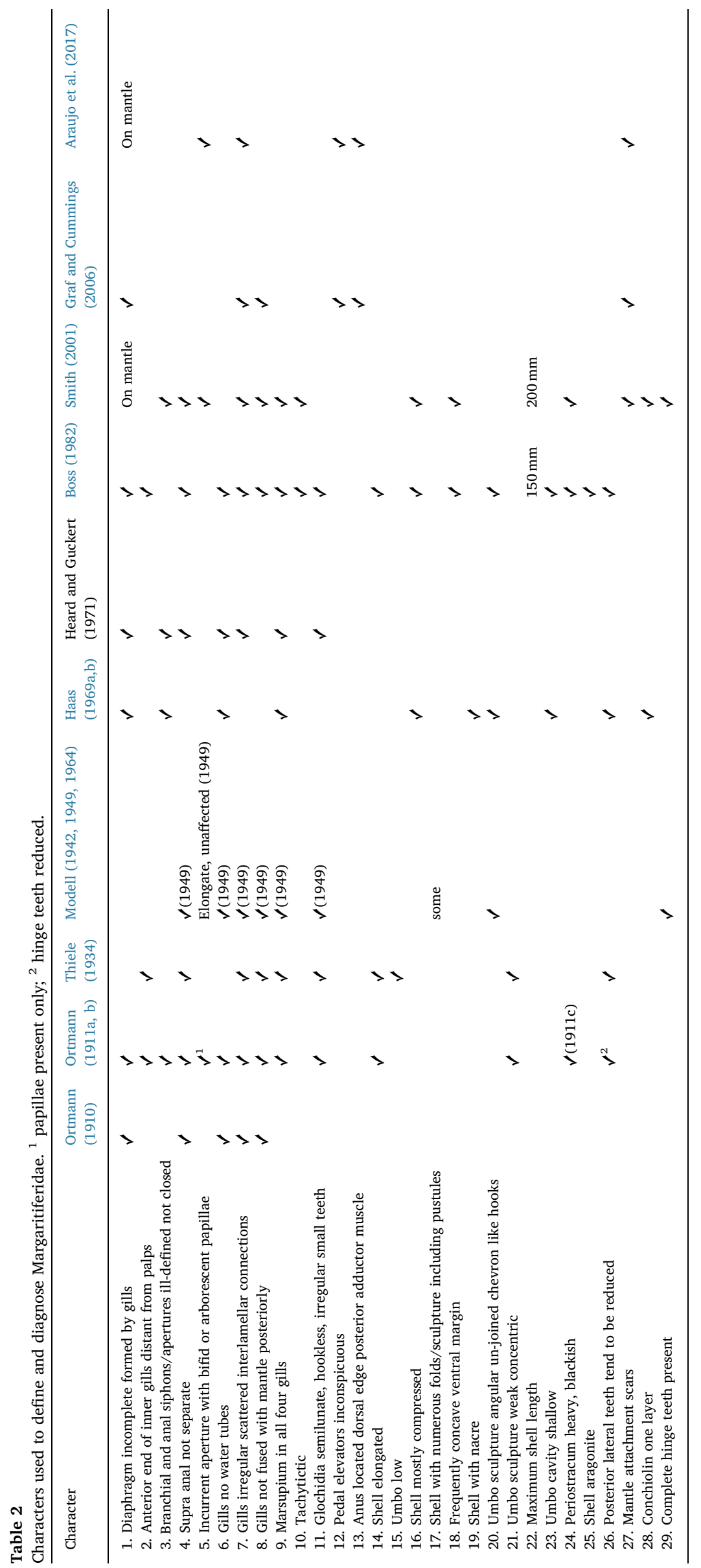


delayed diversification processes within the family, although the diversification rates in margaritiferids have never been tested to date.

\subsection{Historical description and classification of some incertae sedis Unionidae taxa}

Although recent phylogenetic works have increased our knowledge on the position of many Unionida genera from the less studied African and Asian countries (e.g. Pfeiffer and Graf, 2013, 2015; Lopes-Lima et al., 2017a; Bolotov et al., 2017a,b), the most comprehensive revision of the Unionidae classification to date placed 42 genera as incertae sedis (Lopes-Lima et al., 2017a). These included Gibbosula (Simpson 1900), whose type species was first described and illustrated by Wood (1815) as Mya crassa from an unknown locality in China and later classified under Gibbosula (i.e. as Gibbosula crassa) within the Unionidae by Simpson (1900). A few years later, another specimen was found in southern China and described as a new species, i.e. Unio (Quadrula) mansuyi Dautzenberg \& Fischer, 1908. Simpson (1914) placed this species under Quadrula and did not associate it with G. crassa. A third specimen was described in 1928 and added to Gibbosula (i.e. Gibbosula confragosa Frierson, 1928) based on conchological similarities with $G$. crassa. In his comprehensive classification of the Unionida, Haas (1969a,b) considered that Gibbosula had been superfluously created by Simpson and listed it as a synonym of Lamprotula, inside the Unionidae. Additionally, Haas (1969a) listed Dautzenberg \& Fischer's species Unio mansuyi as a synonym of Lamprotula crassa.

Simpson (1914) was the first to notice that $G$. crassa presented some typical margaritiferid conchological features (i.e. mantle attachment scars), but due to other distinct characters (e.g., heavy shell, well developed teeth and deep umbo cavity) it was retained within the Unionidae. Later, Morrison (1975) also noted that Gibbosula had the same characters now known to characterize the Margaritiferidae. However, this information was overlooked by most malacologists who continued to follow Haas (1969a) and kept G. crassa and G. confragosa under Lamprotula (e.g. Prozorova et al., 2005; Graf and Cummings, 2007). Finally, some authors recently described conchological differences between the two Gibbosula species and Lamprotula, and recognized Gibbosula as a separate genus within Unionidae (He and Zhuang, 2013; Graf and Cummings, 2018). Furthermore, based on conchological similarities, a third species of Gibbosula was recently described, i.e. Gibbosula nanningensis (Qian et al., 2015).

The genus Lamprotula was recently revealed to be polyphyletic and divided into Lamprotula s.s. and Aculamprotula (Zhou et al., 2007; Pfeiffer and Graf, 2013). These authors also noted that all species of Lamprotula should be comprehensively analyzed in order to clarify their status and relationships. For instance, based on molecular analyses, Lamprotula rochechouartii has been moved to Margaritiferidae (Huang et al., 2017). In addition, morphological and molecular characteristics of six specimens of $G$. crassa collected from Bang River, Cao Bang Province, Vietnam in 2016, suggested that the species did not belong to the Unionidae but to the Margaritiferidae (Bogan and Do, 2016). The reassignment of these two Asian species (i.e. L. rochechouartii and G. crassa) from the Unionidae to the Margaritiferidae raises the question whether there are other overlooked species of Margaritiferidae within this group. To address this issue, the congeneric G. confragosa and $L$. rochechouartii shell types were here analyzed as well as other types of Lamprotula sp. for potentially misplaced margaritiferids.

Under these considerations, the present study aimed to: (i) perform a detailed morphological characterization of collected $G$. crassa specimens, and available museum specimens of all Margaritiferidae, Lamprotula and Gibbosula; (ii) sequence and characterize the whole Ftype mitogenome of $G$. crassa; (iii) produce a robust phylogeny of the Margaritiferidae using five (nuclear and mitochondrial) markers and discuss the systematics and taxonomy within the family; (iv) compare anatomical, conchological and ecological characters within and among all retrieved clades; and (v) describe the potential origin and ancient radiations of the Margaritiferidae and detect the most probable ancestral geographic areas on the basis of a new multi-locus fossil-calibrated phylogenetic model, using the most complete sampling of taxa to date and an expanded calibration dataset.

\section{Materials and methods}

\subsection{Sampling and museum specimens}

Six specimens of $G$. crassa were collected during a survey in northern Vietnam in the Bang River, Cao Bang Province, Vietnam, in 2016. Specimens were deposited as vouchers at the North Carolina Museum of Natural Sciences, United States of America (NCSM 102193, 102194) and at the Institute of Ecology and Biological Resources, Hanoi, Vietnam (IEBR-FM 01-03). Museum specimens of Gibbosula, Lamprotula and Margaritiferidae, including the type specimens of Unio mansuyi and G. confragosa, were analyzed for morphology and/or genetics (Table 3 and Supplementary Table 1). Foot tissue samples were collected and preserved in $96 \%$ ethanol for DNA extraction.

\subsection{DNA extractions, sequencing, assembly and annotation}

DNA was extracted from foot samples of two G. crassa individuals and other margaritiferid specimens (Table 3) following Froufe et al. (2016). The complete F-type mitogenome of a single G. crassa sample was then sequenced and assembled using an established pipeline (Gan et al., 2014). Mitochondrial gene annotations were performed using MITOS (Bernt et al., 2013). The final tRNAs gene limits were rechecked with ARWEN (Laslett and Canbäck, 2008). Finally, in-house scripts were applied to adjust the mtDNA protein-coding limits since MITOS seems to underestimate gene length (for details, go to https://figshare. $\mathrm{com} / \mathrm{s} / \mathrm{a} 756 \mathrm{ef19cec8f65d506a)}$. The whole mitogenome sequence has been deposited in GenBank (MH319826). The mitogenome was then visualized using GenomeVx (Conant and Wolfe, 2008) (Supplementary Fig. 1). The mitochondrial 16S rRNA and Cytochrome $c$ Oxidase I (COI), and the nuclear 18S rRNA, 28S rRNA, and Histone 3 (H3) gene fragments were amplified from the extracted gDNAs of both $G$. crassa and the remaining margaritiferid species, following the conditions described in Bolotov et al. (2016) and Araujo et al. (2017).

\subsection{Phylogenetic analyses}

Individual alignments were performed for each of the five markers: COI - 654 bp, 16S - 475 bp, $18 \mathrm{~S}-1778$ bp, $28 \mathrm{~S}-307 \mathrm{bp}$, and H3 $327 \mathrm{bp}$. Each alignment was constructed with up to two representatives from all available Margaritiferidae species, including GenBank sequences (Table 3). Representative species from each of the families of the Unionida and from Neotrigonia, Trigoniidae, the marine sister group of the Unionida (Giribet and Wheeler, 2002), were included as outgroups (Table 3). All individual datasets were aligned using the standalone version of GUIDANCE2 (Sela et al., 2015) with the MAFFT multiple sequence global pair alignment algorithm (Katoh and Standley, 2013). The following GUIDANCE parameters were used: GUIDANCE score algorithm; 100 bootstrap replicates; and a column cut-off score of 0.8. Substitution saturation tests for all codon positions were accomplished in the protein-coding loci (COI, and H3) as implemented in DAMBE 6 (Xia, 2017). Phylogenetic analyses were then performed by Bayesian Inference (BI) and Maximum Likelihood (ML) on 13 partitioned datasets from a single marker to a combination of markers as follows: (1) combined dataset 1: COI ( 3 codons $)+16 \mathrm{~S}+18 \mathrm{~S}+$ $28 \mathrm{~S}+\mathrm{H} 3$ (3 codons); (2) combined dataset 2 : COI $+16 \mathrm{~S}+18 \mathrm{~S}+28 \mathrm{~S}$ + H3; (3) mtDNA 1: COI (3 codons) + 16S; (4) mtDNA 2: COI + 16S; (5) COI ( 3 codons); (6) COI; (7) 16S; (8) nDNA: $18 \mathrm{~S}+28 \mathrm{~S}+\mathrm{H} 3(3$ codons); (9) nDNA: $18 \mathrm{~S}+28 \mathrm{~S}+\mathrm{H} 3$; (10) 28S; (11) 18S; (12) H3 (3 codons); and (13) H3. For the BI analyses, the best-fit models of nucleotide substitution for each partition were previously selected 
Table 3

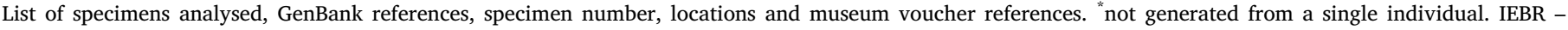

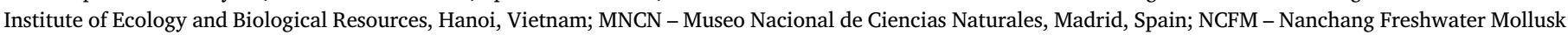

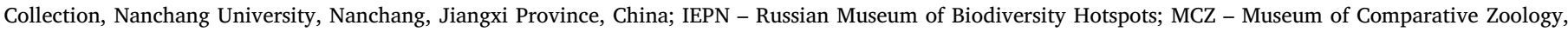
Harvard University, USA; UAUC - University of Alabama Unionid Collection, USA; BivAToL - Bivalve Tree of Life Project, USA.

\begin{tabular}{|c|c|c|c|c|c|c|c|c|}
\hline Taxon & Specimen & COI & $16 \mathrm{~S}$ & $18 \mathrm{~S}$ & $28 \mathrm{~S}$ & H3 & Location & Voucher \\
\hline \multicolumn{9}{|l|}{ UNIONIDA } \\
\hline \multicolumn{9}{|l|}{ MARGARITIFERIDAE } \\
\hline \multicolumn{9}{|l|}{ GIBBOSULINAE } \\
\hline Gibbosula crassa & 1 & MH293546 & MH293536 & MH293539 & MH293542 & MH293549 & Bang River, Cao Bang, Vietnam & IEBR FM GC01 \\
\hline Gibbosula crassa & 2 & MH293547 & MH293537 & MH293540 & MH293543 & MH293550 & Bang River, Cao Bang, Vietnam & IEBR FM GC03 \\
\hline Gibbosula laosensis & 1 & KU763224 & KU763193 & KU763255 & KU763298 & KU763342 & Mun River, Thailand & \\
\hline Gibbosula laosensis & 2 & KU763225 & KU763194 & KU763256 & KU763299 & KU763343 & Luang Prabang, Laos & $\begin{array}{l}\text { MNCN 15.07/12038 } \\
\text { (N1687) }\end{array}$ \\
\hline Gibbosula rochechouartii & 1 & MF072498 & MF072505 & MF072519 & MF072512 & MF072526 & Poyang Lake, Yangtze, China & \\
\hline Gibbosula rochechouartii & 2 & MF072502 & MF072509 & MF072523 & MF072516 & MF072530 & Poyang Lake, Yangtze, China & \\
\hline \multicolumn{9}{|l|}{ MARGARITIFERINAE } \\
\hline Cumberlandia monodonta & 1 & AY579131 & AY579089 & AY579105 & AY579121 & AY579144 & Missouri, USA & \\
\hline Cumberlandia monodonta & 2 & MH293545 & MH293535 & MH293538 & MH293541 & MH293548 & Meramec River, Missouri, USA & \\
\hline Margaritifera dahurica & 1 & KJ161516 & KJ943526 & КT343730 & КT343738 & AY579133 & Ilistaya River, Primorye, Russia & IEPN d0088/6 \\
\hline Margaritifera dahurica ${ }^{*}$ & 2 & KJ161520 & KJ943527 & KJ943531 & MH293544 & MH293551 & Ilistaya River, Primorye, Russia & IEPN d0089/2 \\
\hline Margaritifera falcata & 1 & AY579128 & AY579085 & AY579101 & AY579117 & AY579141 & Idaho, USA & MCZ DNA100844 \\
\hline Margaritifera falcata & 2 & AY579127 & AY579084 & AY579100 & AY579116 & AY579140 & $\begin{array}{l}\text { North Umpqua River, Oregon, } \\
\text { USA }\end{array}$ & MCZ DNA100699 \\
\hline Margaritifera hembeli & 1 & KU763218 & KU763189 & KU763250 & KU763293 & KU763336 & Valentine Creek, Louisiana, USA & \\
\hline Margaritifera hembeli & 2 & KU763219 & KU763190 & KU763251 & KU763294 & KU763337 & Brown Creek, Louisiana, USA & \\
\hline Margaritifera laevis & & KU763222 & KU763192 & KU763253 & KU763296 & KU763340 & Iwaizumi, Honshu, Japan & MNCN-FW1502-2 \\
\hline Margaritifera margaritifera & 1 & KU763227 & KU763196 & KU763258 & KU763301 & KU763345 & Locust Creek, Pennsylvania, USA & \\
\hline Margaritifera margaritifera & 2 & AF303342 & AF303301 & KU763274 & KU763317 & KU763360 & Nore River, Ireland & MNCN FW1490-1 \\
\hline Margaritifera marrianae & & KU763243 & KU763214 & KU763283 & KU763326 & KU763369 & Hunter Creek, Alabama, USA & UAUC 1651 \\
\hline Margaritifera middendorffi & 1 & AY579124 & AY579081 & AY579092 & AY579108 & AY579134 & Iturup, Kuril Islands, Russia & MCZ DNA100685 \\
\hline Margaritifera middendorffi & 2 & KJ161547 & KJ943528 & КT343726 & КT343735 & MH293552 & $\begin{array}{l}\text { Nachilova River, Kamchatka, } \\
\text { Russia }\end{array}$ & IEPN d0099/6 \\
\hline Pseudunio auricularius & 1 & AY579125 & AY579083 & AY579097 & AY579113 & AY579137 & Ebro River, Tarragona, Spain & MCZ DNA100674 \\
\hline Pseudunio auricularius & 2 & AF303309 & AF303274 & KU763247 & KU763290 & KU763333 & Canal Imperial, Zaragoza, Spain & MNCN-FW1238-12 \\
\hline Pseudunio homsensis & & KX550090 & KX550092 & KX550088 & KX550086 & MH293553 & Karasu River, Turkey & \\
\hline Pseudunio marocanus & 1 & EU429678 & EU429689 & KU763281 & KU763324 & KU763367 & Oum Er Rbia River, Morocco & MNCN N1254 \\
\hline Pseudunio marocanus & 2 & EU429679 & EU429691 & KU763282 & KU763325 & KU763368 & Laabid River, Morocco & MNCN N1264 \\
\hline \multicolumn{9}{|l|}{ UNIONIDAE } \\
\hline Lampsilis cardium & & KX713472 & KX713226 & KX713305 & KX713394 & KX713547 & Illinois, USA & BivAToL-421 \\
\hline Potomida littoralis & & KP217871 & КР217981 & KU763287 & KU763330 & KU763373 & Cadiz, Spain & MNCN N706 \\
\hline Unio pictorum & & KC429109 & KC429266 & KC429349 & KC429447 & KC429186 & Thames River, UK & BivAToL-204 \\
\hline \multicolumn{9}{|l|}{ HYRIIDAE } \\
\hline Hyridella australis & & KX713467 & KX713224 & KX713301 & KX713389 & KX713545 & New South Wales, Australia & BivAToL-378 \\
\hline Triplodon corrugatus & & KX713505 & KX713262 & KX713352 & KX713438 & KX713585 & Peru & BivAToL-380 \\
\hline Velesunio ambiguus & & KC429106 & KC429263 & KC429346 & KC429444 & KC429183 & New South Wales, Australia & BivAToL-379 \\
\hline \multicolumn{9}{|l|}{ MULLERIIDAE } \\
\hline Anodontites elongata & & KX713444 & KX713190 & KX713268 & KX713357 & KX713512 & Peru & BivAToL-323 \\
\hline Lamproscapha ensiformis & & KX713471 & KX713225 & KX713304 & KX713393 & KX713546 & Peru & BivAToL-382 \\
\hline \multicolumn{9}{|l|}{ ETHERIIDAE } \\
\hline Etheria elliptica & & KX713462 & KX713219 & KX713296 & KX713384 & KX713540 & Zambia & BivAToL-401 \\
\hline \multicolumn{9}{|l|}{ IRIDINIDAE } \\
\hline Aspatharia pfeifferiana & & KC429107 & KC429264 & KC429347 & KC429445 & KC429184 & Chambeshi River, Zambia & BivAToL-330 \\
\hline Chambardia wahlbergi & & KX713448 & KX713202 & KX713277 & KX713365 & KX713520 & Zambia & BivAToL-405 \\
\hline Mutela hargeri & & KX713482 & KX713237 & KX713317 & KX713405 & KX713559 & Zambia & BivAToL-401 \\
\hline \multicolumn{9}{|l|}{ TRIGONIIDA } \\
\hline \multicolumn{9}{|l|}{ TRIGONIIDAE } \\
\hline Neotrigonia lamarckii & & KC429105 & KC429262 & KC429345 & KC429443 & KC429182 & $\begin{array}{l}\text { North Stradbroke Island, } \\
\text { Australia }\end{array}$ & BivAToL-97 \\
\hline Neotrigonia margaritacea & & U56850 & DQ280034 & AF411690 & AF411689 & AY070155 & Tasmania, Australia & \\
\hline
\end{tabular}

(Supplementary Table 2), under the Bayesian Information Criterion (BIC) using JModelTest 2.1.10 (Darriba et al., 2012). BI analyses were performed in MrBayes v3.2.6 (Ronquist et al., 2012) using the previously selected models. Analyses were initiated with program-generated trees and four Markov chains with default incremental heating. Two independent runs of $20 \times 10^{6}$ generations were sampled at intervals of 1,000 generations producing a total of 20,000 trees. Burn-in was determined upon convergence of log likelihood and parameter values using Tracer 1.6 (Rambaut et al., 2014). For the ML phylogenetic analyses, sequences were analyzed in RaxML 8.0.0 (Stamatakis, 2014) with 1,000 bootstrap replicates, assuming a GTR $+\mathrm{G}+\mathrm{I}$ model for each partition.

\subsection{Morphological and ecological assessments}

To evaluate the systematics within Margaritiferidae and detect other potential margaritiferid species, detailed conchological and anatomical characters were evaluated on newly collected $G$. crassa specimens and on museum specimens of Gibbosula, Lamprotula and Margaritiferidae, including the type specimens of Unio mansuyi and G. confragosa. Bibliographic data on the major ecological and physiological traits were also compiled for all margaritiferid species (Table 4). To characterize and compare glochidial size, the glochidial size index (Gln) was calculated following Lopes-Lima et al. (2017a). 
Table 4

Biological and ecological characters. (Gln) glochidial size índex. Superscripts: ${ }^{\mathrm{U}}$ unknown; ${ }^{\mathrm{R}}$ rivers; ${ }^{\mathrm{L}}$ lakes.

\begin{tabular}{|c|c|c|c|c|c|c|c|}
\hline & Host fish & $\begin{array}{l}\text { Glochidia size } \\
\text { (Gln) }\end{array}$ & Principal Habitats & Flow & Substrate & Water chemistry & References \\
\hline G. confragosa & $\mathrm{U}$ & $\mathrm{U}$ & Rivers-floodplain ${ }^{\mathrm{L}}$ & $\mathrm{u}$ & $\mathrm{u}$ & $\mathrm{U}$ & He and Zhuang (2013) \\
\hline G. crassa & $\mathrm{U}$ & $\mathrm{u}$ & Medium $^{\mathrm{R}}$ & Moderate-strong & Boulder, cobble & Hard & Bogan and Do (2016) \\
\hline G. laosensis & $\mathrm{U}$ & $\mathrm{u}$ & Headwater ${ }^{R}$ & Moderate-strong & $\begin{array}{l}\text { Sand, gravel } \\
\text { boulder }\end{array}$ & $\begin{array}{l}\text { Moderate-hard } \\
\text { oligotrophic }\end{array}$ & Bolotov et al. (2014) \\
\hline G. rochechouartii & $\mathrm{U}$ & $\mathrm{U}$ & Rivers-floodplain ${ }^{\mathrm{L}}$ & Slow-Moderate & Hard mud & Soft-moderate & Do (2011a) \\
\hline G. polysticta & $\mathrm{U}$ & $\mathrm{u}$ & Rivers-floodplain ${ }^{\mathrm{L}}$ & Slow-Moderate & $\mathrm{U}$ & Oligotrophic & Do (2011b) \\
\hline C. monodonta & Hiodontidae & 0.004 & Medium-large $^{\mathrm{R}}$ & Moderate-strong & $\begin{array}{l}\text { Under flat rocks } \\
\text { rock crevices }\end{array}$ & Hard & $\begin{array}{l}\text { S. McMurray pers. com. Sietman et al. (2017) } \\
\text { Williams et al. (2008) }\end{array}$ \\
\hline M. dahurica & Salmonidae & 0.006 & Headwater $^{\mathrm{R}}$-large ${ }^{\mathrm{R}}$ & Moderate-strong & Sand, gravel & $\begin{array}{l}\text { Oligotrophic } \\
\text { soft }\end{array}$ & Bolotov et al. (2015) \\
\hline M. falcata & Salmonidae & 0.006 & Headwater ${ }^{\mathrm{R}}$-large $\mathrm{e}^{\mathrm{R}}$ & Moderate-strong & Sand, gravel & $\begin{array}{l}\text { Oligotrophic } \\
\text { soft }\end{array}$ & Nedeau et al. (2009) \\
\hline M. hembeli & Esocidae & $\mathrm{u}$ & Headwater $^{\mathrm{R}}$ & Moderate & Sand, gravel & $\begin{array}{l}\text { Oligotrophic } \\
\text { soft }\end{array}$ & Paul Johnson pers. com. \\
\hline M. laevis & Salmonidae & 0.004 & Headwater ${ }^{\mathrm{R}}$-large $\mathrm{R}^{\mathrm{R}}$ & Moderate-strong & Sand, gravel & $\begin{array}{l}\text { Oligotrophic } \\
\text { soft }\end{array}$ & Bolotov et al. (2015) \\
\hline M. margaritifera & Salmonidae & 0.005 & Headwater $^{\mathrm{R}}$-large ${ }^{\mathrm{R}}$ & Moderate-strong & $\begin{array}{l}\text { Sand, gravel } \\
\text { cobble }\end{array}$ & $\begin{array}{l}\text { Oligotrophic } \\
\text { soft }\end{array}$ & Lopes-Lima et al. (2017c) \\
\hline M. marrianae & Esocidae & 0.002 & Headwater ${ }^{\mathrm{R}}$ & Slow-moderate & Sand, gravel & $\begin{array}{l}\text { Oligotrophic } \\
\text { soft }\end{array}$ & Paul Johnson pers. com. \\
\hline M. middendorffi & Salmonidae & 0.006 & Headwater ${ }^{\mathrm{R}}$-large $\mathrm{e}^{\mathrm{R}}$ & Slow-moderate & Sand, gravel & $\begin{array}{l}\text { Oligotrophic } \\
\text { soft }\end{array}$ & Bolotov et al. (2015) \\
\hline P. auricularius & $\begin{array}{l}\text { Acipenseridae } \\
\text { Blenniidae } \\
\text { Gasterosteidae }\end{array}$ & 0.018 & $\begin{array}{l}\text { Middle-lower } \\
\text { Moderate-large }^{\mathrm{R}}\end{array}$ & Moderate-strong & Sand, gravel & Hard & $\begin{array}{l}\text { Prié et al. (2010) } \\
\text { Prié et al. (2018) }\end{array}$ \\
\hline P. homsensis & U & $\mathrm{U}$ & $\begin{array}{l}\text { Middle-lower } \\
\text { Moderate-large }^{\mathrm{R}}\end{array}$ & Slow-moderate & Silt & Mesotrophic & Vikhrev et al. (2017) \\
\hline P. marocanus & $\mathrm{u}$ & $\mathrm{u}$ & $\begin{array}{l}\text { Middle-lower } \\
\text { Moderate-large }^{\mathrm{R}}\end{array}$ & Moderate-strong & Gravel, cobble & Hard & Sousa et al. $(2016,2018)$ \\
\hline
\end{tabular}

\subsection{Divergence time estimates}

The acceptance of a global molecular clock to our multi-gene data set was estimated using the maximum likelihood test of MEGA6 (Tamura et al., 2013), which revealed that the null hypothesis of equal evolutionary rate throughout the tree was rejected $(p<0.001)$. Thus, the time-calibrated haplotype-level Bayesian phylogeny was reconstructed in BEAST v. 1.8.4 based on multiple fossil calibration points using a lognormal relaxed clock algorithm with the Yule speciation process as the tree prior (Drummond et al., 2006, 2012; Drummond and Rambaut, 2007). Calculations were performed at the San Diego Supercomputer Center through the CIPRES Science Gateway (Miller et al., 2010). A fossil-calibrated ultrametric tree was obtained using BEAST v. 1.8.4. Similar settings were assigned to nine partitions ( 3 codons of $\mathrm{COI}+16 \mathrm{~S}$ rRNA + 18S rDNA + 28S rDNA + three codons of H3) as in the MrBayes analyses. The eight fossil calibrations were used for timing of the phylogeny (Supplementary Tables 3 and 4). Priors for out-group taxa were designated using a "Monophyly" option of BEAUti v. 1.8.4 (Drummond et al., 2012) as follows: (Trigoniidae, (Unionida)). Four replicate BEAST searches were conducted, each with 30 million generations. The trees were sampled every 1000th generation. The log files were checked visually with Tracer v. 1.6 for an assessment of the convergence of the MCMC chains and the effective sample size of parameters (Rambaut et al., 2014). The first $10 \%$ of trees were discarded as an appropriate burn-in. Almost all ESS values were recorded as $>1000$, with a few values as $>250-800$ and two values as $>100$; the subsequent distributions were similar to the prior distributions. The resulting tree files from four independent analyses were compiled with LogCombiner v. 1.8.4 (Drummond et al., 2012). The maximum clade credibility tree was obtained from 108,004 post-burn-in Bayesian trees using TreeAnnotator v. 1.8.4 (Drummond et al., 2012).

\subsection{Ancestral geographic area reconstructions}

Ancestral geographic area patterns were tested using three different approaches, i.e., Statistical Dispersal-Vicariance Analysis (S-DIVA), Dispersal-Extinction Cladogenesis (Lagrange configurator, DEC), and Statistical Dispersal-Extinction Cladogenesis (S-DEC) implemented in RASP v. 3.2 (Yu et al., 2015). The set of 108,004 fossil-calibrated binary trees that were combined from four runs of BEAST v. 1.8.4 (see above), was used for the ancestral area reconstruction. The user-specified, fossil-calibrated consensus tree, which was obtained based on this set of trees using TreeAnnotator v. 1.8.4 (see above), was used as a condensed tree. Outgroup sequences were removed from all datasets, using the appropriate option of RASP v. 3.2. Only a single sequence for each ingroup species was used for the analyses.

Six possible geographic areas of the in-group taxa were coded as follows: (A) Southeast Asia; (B) East Asia; (C) western North America; (D) eastern North America; (E) Mediterranean Region (South Europe, Middle East, and Morocco); and (F) Europe. Seven geographically unreliable distribution constrains were excluded from the input matrix as follows: Southeast Asia - western North America (AC), Southeast Asia eastern North America (AD), Southeast Asia - Mediterranean Region (AE), Southeast Asia - Europe (AF), East Asia - eastern North America (BD), western North America - Mediterranean Region (CE), and western North America - Europe (CF). Geographic areas were assigned to the species as follows: Southeast Asia - Gibbosula laosensis, East Asia G. crassa, G. rochechouartii, Margaritifera dahurica, M. laevis, and M. middendorffi, western North America - M. falcata, eastern North America - Cumberlandia monodonta, Margaritifera marrianae, and $M$. hembeli, and Mediterranean Region $-P$. auricularius, $P$. homsensis, and Pseudunio marocanus. Taking into account the broad trans-Atlantic distribution of Margaritifera margaritifera, we assigned the 'DEF' range for this species.

The S-DIVA models were calculated with the following parameters: max areas $=2$; allow reconstruction with $\max$ reconstructions $=100$; 


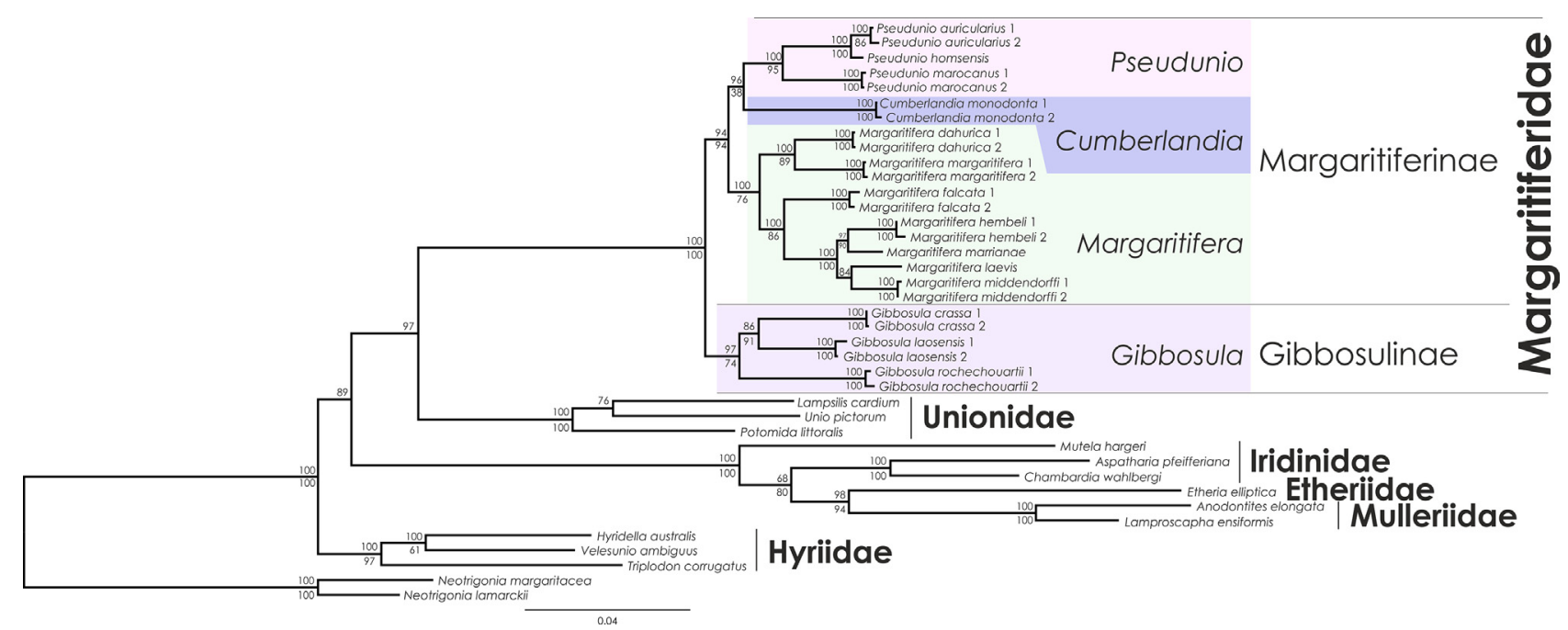

Fig. 1. Phylogenetic tree of the Paleoheterodonta obtained by Bayesian Inference (BI) and Maximum likelihood (ML) analyses of the combined (COI [3 codons] + $16 \mathrm{~S}+18 \mathrm{~S}+28 \mathrm{~S}+\mathrm{H} 3[3$ codons]) dataset. Support values above the branches are posterior probabilities and bootstrap support below. Numbers after species names refer to specimen number (see Table 3).

$\max$ reconstructions for final tree $=1000$; and allowing extinctions. The DEC and S-DEC analyses were run with default settings and max areas $=2$. In addition to the evaluations obtained from each analysis separately, we used generalized results of all three modeling approaches, which were combined using an algorithm implemented in RASP v. 3.2.

\subsection{Diversification rate analyses}

The diversification rates were assessed based on the combined Bayesian phylogeny across the primary clades of the Margaritiferidae and the entire family. The set of 108,004 fossil-calibrated chronograms that were combined from four runs of BEAST v. 1.8.4 (see above) was used to construct semi-logarithmic lineage-through-time (LTT) plots in R-package 'ape' v. 4.0 (Paradis, 2012; Popescu et al., 2012) with the supplement of 'paleotree' v. 2.7 (Bapst, 2012). We did not include a simulation for missing taxa (Pybus and Harvey, 2000), because we assumed that our samples of the margaritiferid clades are nearly complete.

Two tests of a constant diversification rate for the endemic IndoChinese clades outlined above were calculated using 'ape' v. 4.0 based on the maximum clade credibility tree inferred from BEAST (Paradis, 2012; Popescu et al., 2012). First, the analysis of diversification with three survival models, i.e., a constant diversification model, a variable diversification rate through time (Weibull model), and diversification changes at a specified time point (Paradis, 1997). The delta parameter from the constant rate model of Paradis (1997) was used as mean diversification rates. Additionally, beta values of the Weibull model were tested where $\beta>1$ suggests declining and $\beta<1$ indicates an increasing rate of diversification. Second, the gamma statistic of Pybus and Harvey (2000) was applied. The null hypothesis of constant rate is rejected at the $5 \%$ level if a gamma statistic less than -1.645 , which suggests a significantly decreasing rate of diversification through time (Pybus and Harvey, 2000).

\section{Results}

\subsection{Mitogenome characteristics}

The length of the newly sequenced female mitogenome haplotype of G. crassa $(16,196 \mathrm{bp})$ is within the typical range of Unionida. It includes the 13 protein-coding genes, the gender-specific ORF described for all
Unionida mitogenomes with DUI system, 22 transfer RNA (tRNA) and 2 ribosomal RNA (rRNA) genes (Supplementary Fig. 1).

\subsection{Phylogenetic analyses}

The datasets included combinations of individual alignments (COI: 654 bp, 16S: 471 bp, 18S: 1778 bp, 28S: 309 bp, H3: 327 bp). No indels were observed and no stop codons were found after translating the sequences to amino acids in both $\mathrm{COI}$ and $\mathrm{H} 3$ datasets. All saturation tests showed significantly lower values of ISS than ISS.C (a critical value determined from computational simulation) indicating that the evaluated datasets (COI and H3) are not site saturated and are useful for phylogenetic comparisons. The resulting BI and ML trees of the concatenated $(\mathrm{COI}+16 \mathrm{~S}+18 \mathrm{~S}+28 \mathrm{~S}+\mathrm{H} 3)$ datasets generated the same topology within the ingroup, being the topology of the BI with 9 partitions presented (Fig. 1). With the exception of the Iridinidae, paraphyletic in all analyses, all Unionida families are represented by wellsupported monophyletic clades, including the Margaritiferidae (Fig. 1: Table 5). Within the Margaritiferidae, four well supported clades can be found, identified here as Gibbosula, Cumberlandia, Margaritifera, and Pseudunio (Fig. 1; Table 5). In detail, a first division occurs between a Gibbosula clade ( $G$. rochechouartii $+G$. crassa + G. laosensis) that is well supported in the BI analysis and a clade encompassing all remaining species (Fig. 1; Table 5). This latter clade is further divided into the Cumberlandia clade (C. monodonta) + the Pseudunio clade $(P$. auricularius $+P$. homsensis $+P$. marocanus) and the Margaritifera clade ( $M$. margaritifera, M. dahurica, M. falcata, M. hembeli, M. laevis, M. marrianae, and $M$. middendorffi) (Fig. 1; Table 5). The Margaritifera clade is further subdivided in the clade ( $M$. margaritifera $+M$. dahurica) sister to the "Pacific" clade (M. falcata + (M. hembeli + M. laevis $+M$. marrianae $+M$. middendorffi) (Fig. 1; Table 5).

\subsection{Morphological and ecological analyses}

The literature review identified a total of 29 conchological, anatomical and physiological characters that are common to all analyzed Margaritiferid species and can therefore be used to diagnose the family (Table 2). Graf and Cummings (2006) listed five morphological synapomorphies for Margaritiferidae, characters: 7 - gills irregular scattered interlamellar connections; 8 - gills not fused with mantle posterior; 12 pedal elevator muscle scars inconspicuous; 13 - anus located dorsal edge of posterior adductor muscle; and 27 - mantle attachment scars 


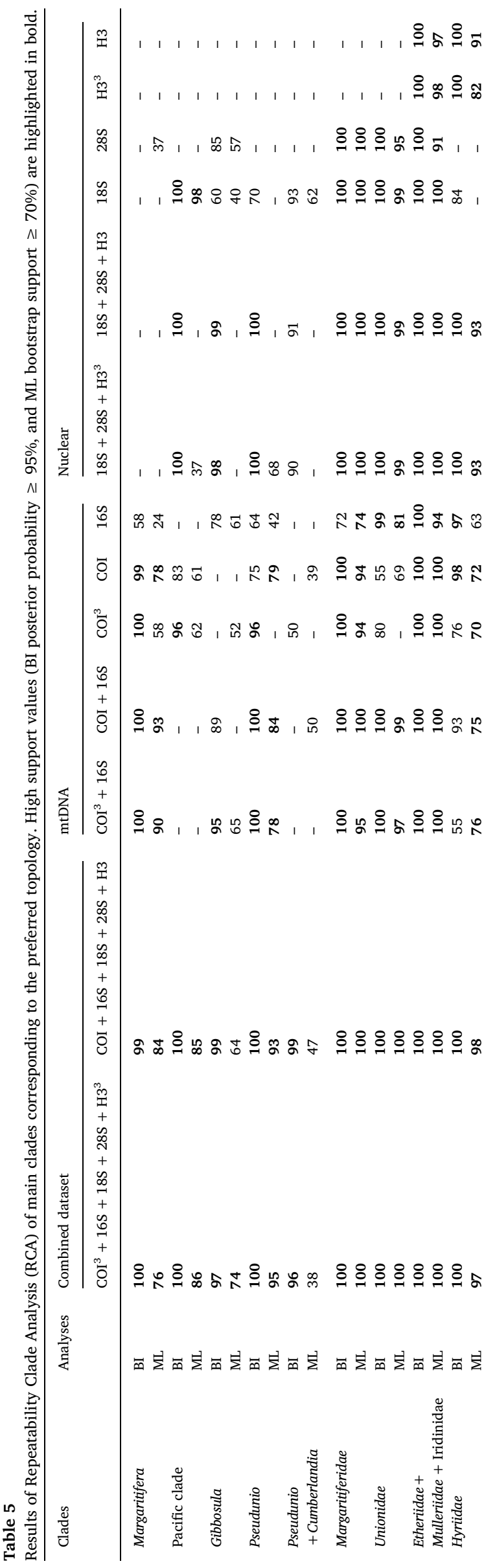

(Table 2). However, only three historically recognized characters, i.e. characters 7, 13 and 27, are synapomorphies of the Margaritiferidae since all other characters can be found in other members of the Unionida, outside the Margaritiferidae. In this study, we identified a new synapomorphy for the Margaritiferidae, i.e. papillae on the external surface of the excurrent aperture. In addition, two molecular characters are also synapomorphic, i.e. the F- and M- mitogenome gene orders (Lopes-Lima et al., 2017b).

Inspection of the conchological features revealed a few similarities across all species (Table 6). Mantle attachment scars were found consistently in all analyzed specimens and nacre color was generally white with the only exceptions being the purple nacre of $M$. falcata and $M$. laevis, and the peach color in the umbonal region of $G$. laosensis (Table 6). Interestingly, most of the inspected characters were distinct and consistent with the four clades retrieved with the phylogenetic analyses (i.e., Gibbosula, Cumberlandia, Margaritifera, and Pseudunio; Table 6). While thin shells are typical for Cumberlandia, thin to medium thick shells can be found in all species of Margaritifera. With the exception of G. laosensis, the remaining species belonging to Pseudunio and Gibbosula have ponderous, thick shells. All species within Cumberlandia, Margaritifera and Pseudunio have shallow and open umbo cavities (e.g., Fig. 2). Conversely, all species of Gibbosula have deep, compressed umbo cavities (e.g., Fig. 2), with the exception of G. laosensis (Table 6). Pseudocardinal teeth are also distinct among the clades (Fig. 2); while Gibbosula and Pseudunio species present large teeth (again with the exception of $G$. laosensis), Margaritifera presents peg-like smaller teeth, and those in Cumberlandia are reduced (Fig. 2). The lateral teeth are consistently well developed in most species across the clades, with a few exceptions (Table 6). However, the lateral teeth of species within Pseudunio and Gibbosula present vertical striations (except for $P$. auricularius), while this character is absent or visible only on the posterior end of laterals of Cumberlandia and Margaritifera species. Shell surface sculpture is also distinct across the genera (Table 6). Species within Cumberlandia, Pseudunio and Margaritifera are generally smooth, without any sculpture, the only exceptions being $M$. hembeli and $M$. marrianae, which present plications on the posterior slope and onto the posterior disk. A distinct pattern can be seen in Gibbosula, where all species, except G. laosensis, are strongly sculptured with pustules, plications or both (Table 6). Shell shape is also distinct among the four clades: species within Gibbosula present a typically convex ventral margin and a variable shell shape; Cumberlandia have a concave ventral margin and elongated shape; Margaritifera shells are elongated and typically straight to slightly concave ventral margin; and finally Pseudunio shells are elongated-oval with a straight to concave ventral margin (Table 6). The umbo in most of the examined shells was eroded and therefore hindered a proper analysis of its sculpture. Nevertheless, concentric bars in the umbo were present in all species, where this feature was visible (Table 6). All of the soft body anatomical traits were similar in all analyzed species (Table 7).

The ecological and other biological characters analyzed here also corroborate the existence of four genera (Table 4). The host fishes of Margaritifera species belong exclusively to the Salmonidae and the closely related Esocidae, while the hosts for Pseudunio and Cumberlandia do not belong to these fish families (Table 4). Cumberlandia uses two species of Hiodontidae, while members of three unrelated families of fish are found to be suitable for $P$. auricularius (Table 4). As for the other two species of Pseudunio, no hosts have yet been identified but no salmonid species occur sympatrically within their current known distribution (Table 4). The fish hosts for Gibbosula species are all unknown, although at least for the Southeast Asian taxa (G. laosensis and G. crassa) do certainly not include Salmonidae, since this family does not occur in this area (Table 4). The glochidia size of $P$. auricularius is much larger than those of Margaritifera and Cumberlandia. Since the glochidia of the other two Pseudunio and all Gibbosula species are undescribed, its utility for systematics still needs to be confirmed (Table 4). The habitat preferences are also distinct among the genera. While Margaritifera species 


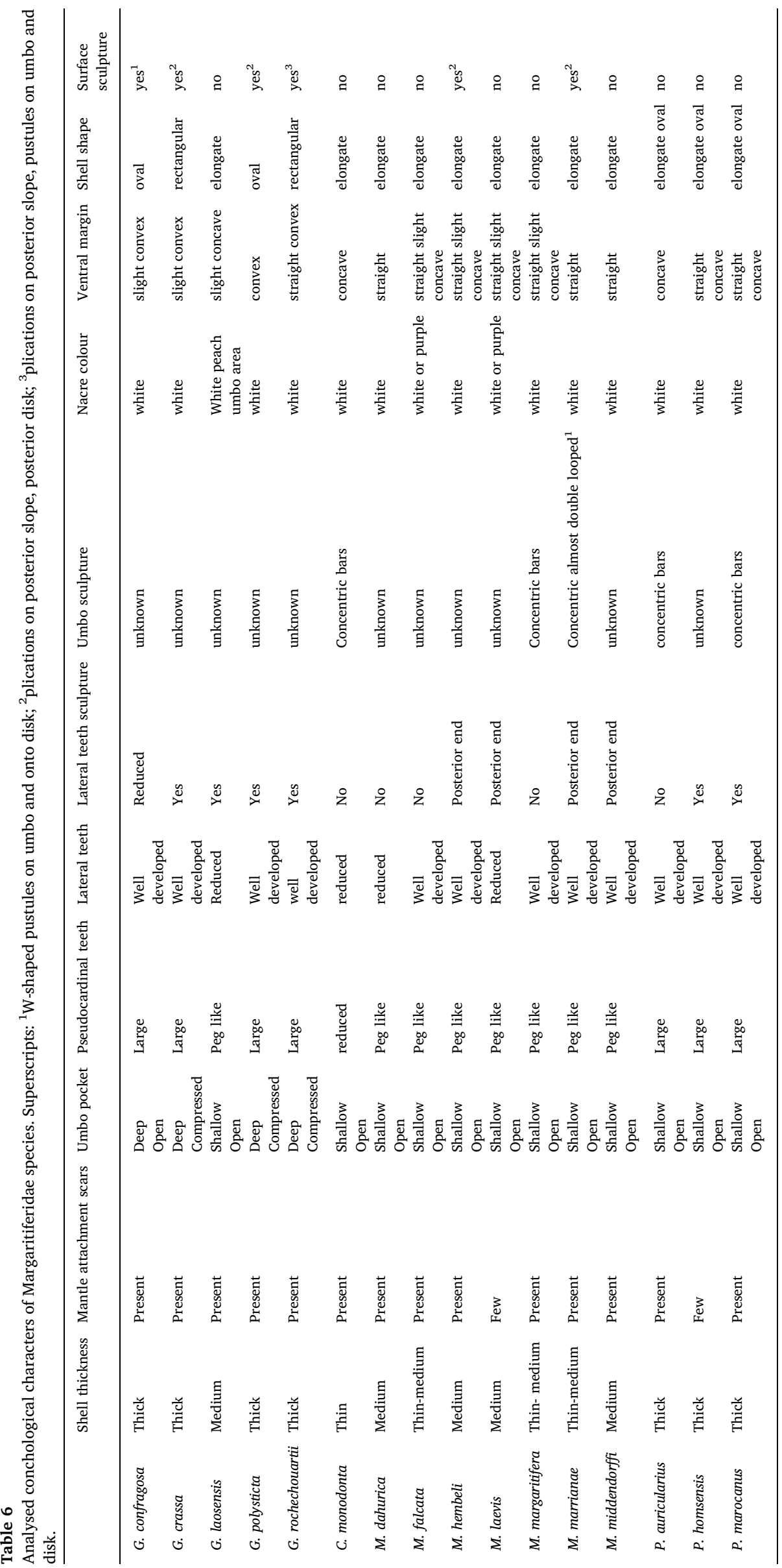


prefer oligotrophic soft-water rivers and are more prevalent in headwaters, Pseudunio generally inhabits the middle to lower sections of moderate to hard-water mesotrophic rivers. Cumberlandia seems to occur in habitats similar to those of Pseudunio (Table 4). However, contrary to all of the other genera it is mostly found in a very particular microhabitat, i.e. under large flat rocks or in rock crevices (Table 4). Gibbosula seems to be much more plastic in its habitat preferences (Table 4) although the ecological features of most species need to be more thoroughly studied.

\subsection{Origin and ancient radiations of the Margaritiferidae}

The combined results of the biogeographic modeling (S-DIVA, DEC and S-DEC approaches) based on the fossil-calibrated chronogram obtained from the relaxed molecular clock analyses returned a robust ancestral area reconstruction for the primary clades of the Margaritiferidae (Figs. 3 and 4, Supplementary Fig. 2, and Table 8). The model suggests that the Margaritiferidae Most Recent Common Ancestor (MRCA) was widespread across the eastern part of Laurasia (probability 55.0\%). The S-DIVA, DEC, and S-DEC models support the same scenario (probability 53.3-58.3\%). The origin of the crown group of the family was placed in the Jurassic (mean age $172 \mathrm{Ma}$, 95\% HPD 168-178 Ma). Based on the combined biogeographic model, the Gibbosulinae MRCA most likely originated in East Asia (probability 78.6\%), with a subsequent vicariance event separating the Southeast Asian species G. laosensis (probability 79.9\%). The origin of the crown group of the subfamily is placed in the mid-Cretaceous (mean age $\sim 103 \mathrm{Ma}, 95 \%$ HPD 86-131 Ma).

The Margaritiferinae MRCA most likely evolved in the East Laurasia (East Asia + Mediterranean Region, probability 62.0\%), with the crown group of the subfamily originating in the Late Jurassic (mean age $\sim 151 \mathrm{Ma}$, 95\% HPD 132-170 Ma). Among Margaritiferinae clades, the crown group of the Cumberlandia + Pseudunio clade most likely originated in the Early Cretaceous (mean age $~ 135 \mathrm{Ma}, 95 \%$ HPD 129-146 Ma) within the Mediterranean region, with subsequent dispersal to eastern North America followed by a vicariance event (probability $45.0 \%$ ). In contrast, S-DIVA model suggests a rather primary broad range of the MRCA across the Mediterranean Region and eastern North America followed by vicariance (probability 100\%). The crown group of Pseudunio originated in the Mediterranean Region (probability 99.9\%) in the Eocene (mean age $47 \mathrm{Ma}$, 95\% HPD 35-66 Ma).

The crown group of Margaritifera is of Late Cretaceous origin (mean age $86 \mathrm{Ma}, 95 \%$ HPD 51-131 Ma) and most likely evolved in East Asia (probability 52.4\%). The sister species pair of $M$. dahurica and $M$. margaritifera diverged in the mid-Eocene (mean age $42 \mathrm{Ma}$, 95\% HPD 34-57 Ma) via a dispersal event forming a continuous trans-Eurasian range of their MRCA followed by a vicariance event (probability $70.4 \%$ ). The origin of the 'Pacific' clade, i.e., M. falcata, M. laevis, $M$. middendorffi, $M$. hembeli, and M. marrianae, is placed near the Paleocene - Eocene boundary (mean age $57 \mathrm{Ma}, 95 \%$ HPD 46-73 Ma). The diversification of this group was largely associated with several dispersal and vicariance events via the Beringian land bridge (probability 49.2-86.0\%).

\subsection{Diversification rates}

The lineage-through-time modeling suggests extremely slow diversification rates in the Margaritiferidae (Fig. 5). The constant-rate test suggests that all clades diversified under the pure-birth (constant) model (Supplementary Table 5). Paradis' test of diversification with three survival models returned a declining diversification rate in Gibbosula and Margaritifera, but not in Pseudunio + Cumberlandia and the Margaritiferidae as a whole (Supplementary Table 5).

\section{Discussion}

\subsection{Definition of the Margaritiferidae}

Since the first definition of the Margaritiferidae by Ortmann, its supposed diagnostic characters have varied considerably (Table 2). Graf and Cummings (2006), based on a molecular (COI $+28 S$ ) and morphological phylogeny, revised margaritiferid synapomorphies noting that there was no previous consensus on characters diagnosing the family Margaritiferidae. These authors retained only five morphological synapomorphies, two conchological (characters 12 and 27, Table 2) and three anatomical (characters 7, 8, and 13, Table 2) characters. All other analyzed characters were considered plesiomorphic (Graf and Cummings, 2006). The main synapomorphies of the family were again re-evaluated by Araujo et al. (2017) (Table 2). They rejected Graf and Cummings (2006) character 12, and considered character 27 as the only conchological synapomorphy for the Margaritiferidae. These authors retained anatomical characters 7,8 , and 13 , but were not able to fully evaluate the anal position in all taxa (see Table 2). Other characters previously used to characterize Margaritiferidae were found in other genera of the Unionidae (Table 2). Finally, a recent mitogenomics study provided the F- and M- type gene-orders of the Margaritiferidae as two additional synapomorphic diagnostic characters (Lopes-Lima et al., 2017b).

In the present study, 29 analyzed characters were common to all margaritiferid species, and therefore can be used to diagnose the family (Table 2). However, only six, i.e. characters 7, 13, and 27 (Table 2), the papillae on the external surface of the excurrent aperture, plus both mitogenome orders are synapomorphies of the Margaritiferidae. All of the other characters can be found on other members of the Unionida and Neotrigonia, outside the Margaritiferidae.

\subsection{Expansion of Margaritiferidae}

Based on morphological and molecular evidence, the family Margaritiferidae is here expanded to 16 species and separated into two subfamilies (i.e. Margaritiferinae and Gibbosulinae) and four genera (i.e. Pseudunio, Cumberlandia, Margaritifera, and Gibbosula) (Fig. 1; Table 9; Supplementary Table 6).

Until recently, two different species of Gibbosula used to be recognized. Firstly, the type species G. crassa was described by Wood (1815) from a specimen collected in an unknown location in China. Since then, only a few specimens of $G$. crassa or its synonym Unio

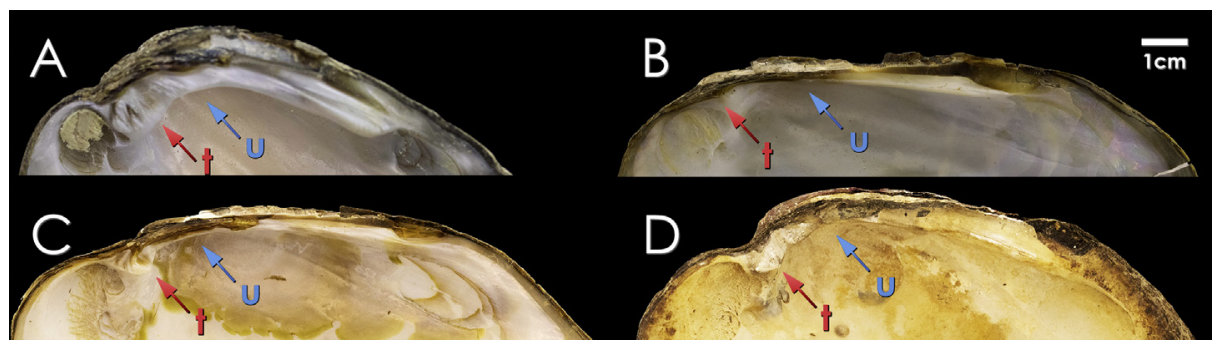

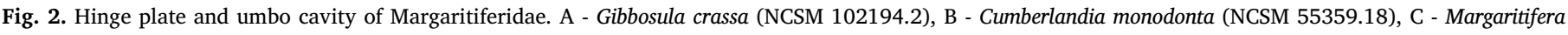
margaritifera, (NCSM 5771.1) D - Pseudunio auricularius (NCSM 44514.2). $\mathrm{t}$ - pseudocardinal teeth, $\mathrm{u}$ - umbo cavity. 
mansuyi have been collected, almost a hundred years ago, in the Bang River, Pearl/Zhu River basin, either in China or Vietnam. During recent surveys, the species was re-discovered but seems to be quite rare and restricted to the middle stretches of Bang River in Cao Bang Province, Vietnam. The second previously recognized species within Gibbosula is G. confragosa, described by Frierson from a single specimen, collected in an uncertain location in north China. Although Prozorova et al. (2005) stated that this species was present in the Yangtze and other Eastern Chinese basins, there is no current evidence of its occurrence in the Yangtze basin. In fact, since $G$. confragosa original description, only one specimen has been collected and described, i.e. a specimen from Lake Baiyangdian, Hai River basin, Hebei province, northern China, previously incorrectly labelled as $U$. microstictus (He and Zhuang, 2013). Beside the shell surface sculpture differences, the disjunct distribution of $G$. confragosa suggests a distinct specific rank.

The newly found specimens and shells of $G$. crassa from Vietnam, here analyzed in detail, feature the characteristics diagnostic and synapomorphies of the Margaritiferidae (Tables 6 and 7). Additionally, the F-type whole mitogenome sequence of one of the specimens collected revealed the typical gene order of the Margaritiferidae (Supplementary Fig. 1), which is unique to this family (Lopes-Lima et al., 2017b). The phylogenetic analyses also confirm the inclusion of $G$. crassa in the Margaritiferidae family, forming a well-supported clade (BI only) with G. laosensis and G. rochechouartii. The shells of G. confragosa and $G$. polysticta present mantle attachment scars exclusive to the Margaritiferidae and were therefore included in the Margaritiferidae (Fig. 1; Table 6) and assigned to Gibbosula due to similarities in shell characteristics with the type species, G. crassa (Table 6). An additional Gibbosula species was recently described, Gibbosula nanningensis (Qian et al., 2015). No specimens of this species were available for evaluation, but based on the description, i.e. the absence of mantle attachment scars and its distinct morphology, we reject its assignment to Gibbosula and therefore to the Margaritiferidae. A detailed systematics description of the species within Gibbosula is presented in Supplementary Appendix 1.

Most of the earlier works on the systematics of margaritiferid genera have failed to retrieve monophyletic clades based on morphological characters alone (Huff et al., 2004). More recently, authors showed that previous generic assignments were inconsistent with the molecular phylogenetic patterns (Huff et al., 2004; Bolotov et al., 2016; Araujo et al., 2017). Whilst all these studies recognized Margaritifera as the single genus within the Margaritiferidae, the rationale for this generic assignment is not always clear. In fact, Bolotov et al. (2016) suggested that the clades found should be assigned to distinct subgenera but maintained Margaritifera as a monotypic genus due to the morphological similarity and moderate level of genetic divergence among the clades.

In the present study, four well supported clades (mainly in the BI analyses) were consistently retrieved using the most comprehensive Margaritiferidae data set analyzed to date (Fig. 1, Table 5). The divergence of these clades, corresponding to the subgenera identified by Bolotov et al. (2016), is older (from late Jurassic to early Cretaceous) than previously believed due to the inclusion of new species and improvements in the fossil calibration (see details below). The present study further revealed a set of consistent morphological, biological and ecological features characteristic to each of the clades. Based on these results, each clade was assigned to a separate generic rank (Fig. 1). The genus Gibbosula includes the species G. crassa, G. confragosa, G. laosensis, G. polysticta, and G. rochechouartii (Fig. 1; Supplementary Table 6). The morphological and ecological features of Gibbosula are consistently more distinct from the other three genera (Tables 6 and 7). This agrees with the molecular phylogeny developed here, which presents two main clades, one with all Gibbosula species and another including (Margaritifera + (Cumberlandia + Pseudunio) (Fig. 1; Table 5). Due to their old divergence (late Jurassic, see below) and clear morphological differences, a subfamily rank was assigned to each of these 


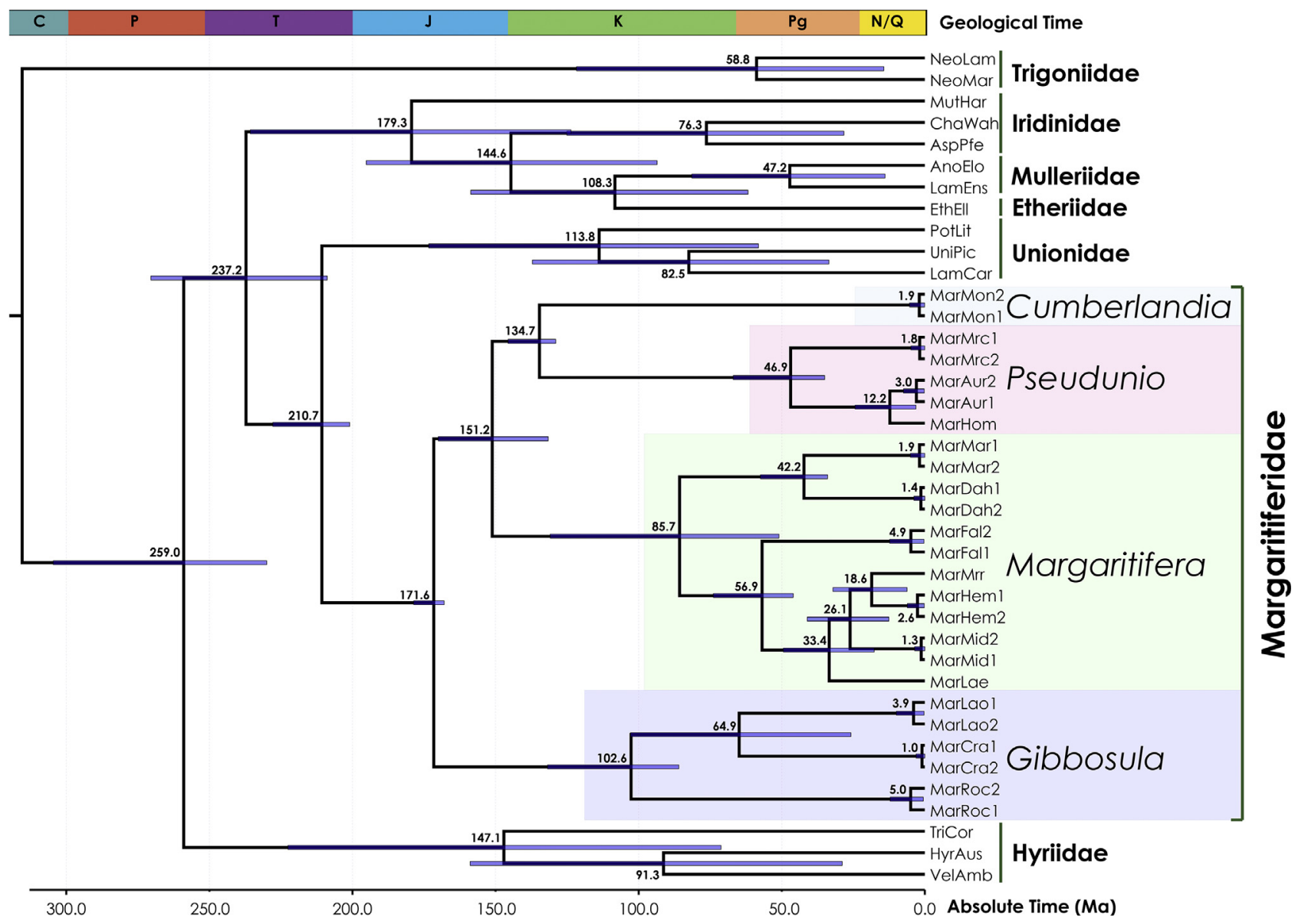

Fig. 3. Fossil-calibrated ultrametric chronogram of the Margaritiferidae calculated under a lognormal relaxed clock model and a Yule process speciation implemented in BEAST 1.8.4 and obtained for the complete data set of mitochondrial and nuclear sequences (nine partitions: three codons of COI $+16 \mathrm{~S}$ rRNA $+18 \mathrm{~S}$ rDNA + $28 \mathrm{~S}$ rDNA + three codons of H3). Bars indicate 95\% confidence intervals of the estimated divergence times between lineages (Ma). Black numbers near nodes are mean ages (Ma). Stratigraphic chart according to the International Commission on Stratigraphy, 2015.

two clades, i.e. Margaritiferinae and Gibbosulinae Bogan, Bolotov, Froufe, Lopes-Lima, new subfamily. Distribution of the two Margaritiferidae subfamilies is mutually exclusive, with the Gibbosulinae being restricted to East and Southeast Asia, while the Margaritiferinae are widespread throughout the rest of the Holarctic (Fig. 6).

\subsection{Systematics}

Margaritiferidae Henderson, 1929 (Ortmann, 1910)

Type genus: Margaritifera Schumacher, 1816

Type species: Mya margaritifera Linnaeus, 1758

Type Locality: "Habitat in totius orbis arctici cataractis" [Arctic habitat in the entire world cataracts] (Linnaeus, 1758).

Comments: This family was split from the Unionidae and four more species were moved from the Unionidae, refining the definition of the family and the variation in shell shape, anatomy and geographic distribution.

Diagnosis: Shell shape varies from elongate to rectangular or oval, shell thickness varies from thin to very thick. Posterior ridge of shell varies from low and rounded to well developed and posterior slope with or without plications, maximum shell length about $200 \mathrm{~mm}$. Umbo sculpture presents angular un-joined chevron-like hooks but Zieritz et al. (2015) have referred to this sculpture as double looped. Periostracum color varies from a dark green to typically black. Lateral teeth vary from vestigial to well-defined with vertical sculpture on all or the posterior portion of the teeth. Pseudocardinal teeth vary from peg like in both valves to thick and massive. Umbo pocket varies from shallow and open to deep and compressed (Fig. 2). Lateral mantle attachment scars are present in varying numbers inside of the pallial line. Nacre varies from white to purple. Mantle free around edges of animal. Apertures open without any mantle fusions to separate the incurrent, excurrent or supra-anal apertures. Branchial and supra-branchial areas not separated posteriorly by gills, but by a diaphragm comprised by a ridge of mantle tissue. Incurrent aperture with arborescent papillae and in at least one species has simple papillae on the external side of incurrent aperture mantle surface typically along the length of the aperture. Excurrent aperture smooth or crenulated, lacking papillae, external side of excurrent aperture mantle surface typically has small papillae along the length of the aperture. Gills attached to the visceral mass only anteriorly. Labial palps falcate in outline. Interlamellar gill connections are "irregularly scattered or forming irregular oblique row, or incomplete septa which run obliquely to the direction of the gill filaments" (Heard and Guckert, 1970). Gills lack water tubes. Marsupium occupies all four gills. Muscular section of the food pigmented either dark red or black. Anus is located on the posterior dorsal margin of the posterior adductor muscle. This family is a short term brooder or tachytictic. Most species are dioecious with only a few listed as hermaphroditic or having hermaphroditic populations. Fish hosts, when known, are Salmonidae, Esocidae, Acipenseridae, Blenniidae, Gasterosteidae, and Hiodontidae, with each margaritiferid genus being restricted to a single or few host fish families. Female and male mitochondrial genome orders are unique for Margaritiferidae and different from Unionidae.

Distribution: The family is found in North America north of 


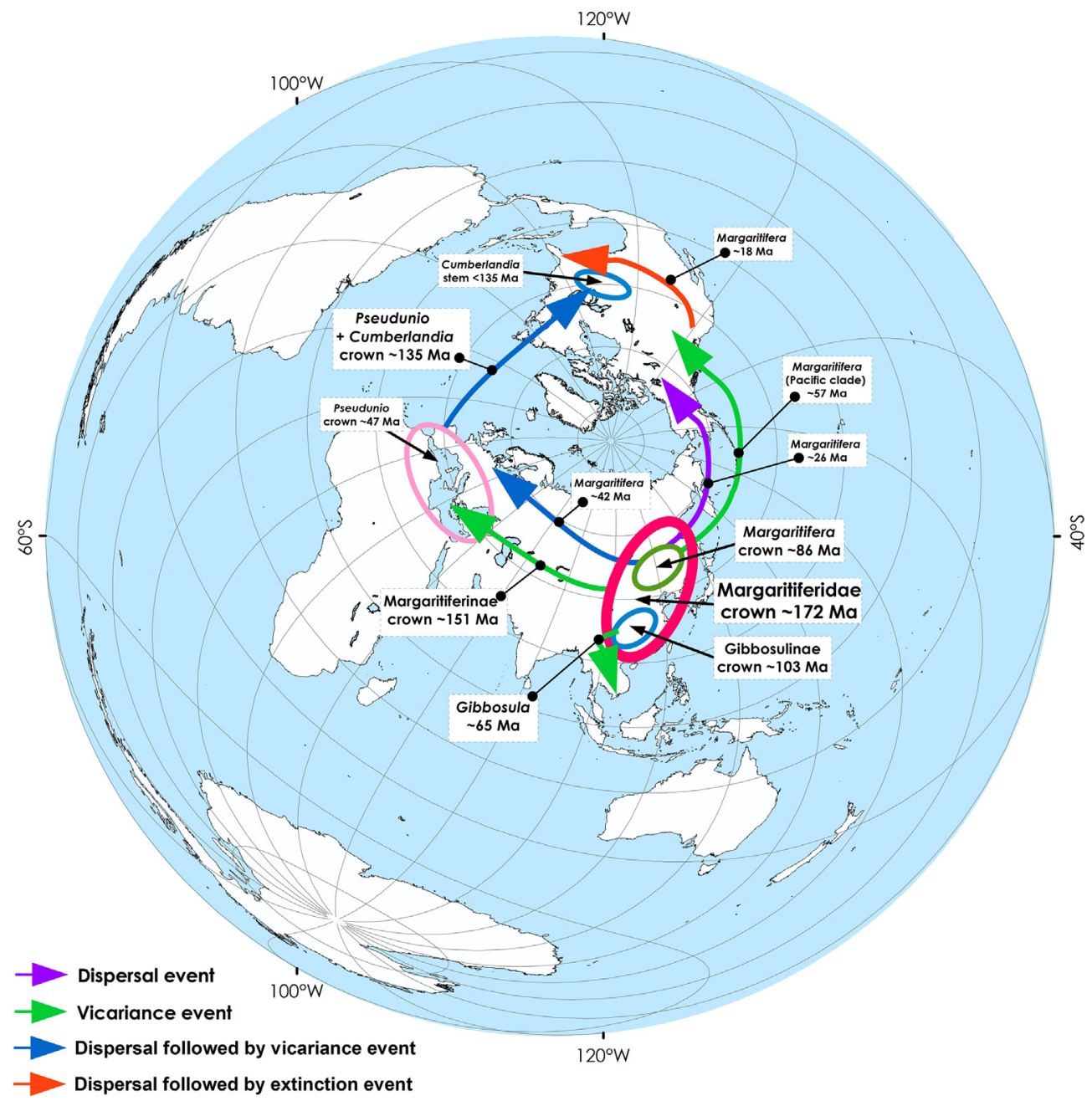

Fig. 4. Simplified scheme of origin and expansion routes inferred across clades of the Margaritiferidae. The black numbers show the mean age of putative expansion events obtained from the multi-locus fossil-calibrated phylogenetic model (see Fig. 3 for details). Circles indicate the putative places of origin of the family and several clades. The map was created using ESRI ArcGIS 10 software (www.esri.com/arcgis); the topographic base of the map was created with ESRI Data and Maps.

Mexico, Western and Northern Europe, western North Africa in Morocco, western Middle-East in Syria, Turkey and Lebanon, Southeast Asia and north to eastern Russia and Japan (Fig. 6).

Subfamily Margaritiferinae Henderson, 1929

Type genus: Margaritifera Schumacher, 1816

Type species: Mya margaritifera Linnaeus, 1758
Type Locality "Habitat in totius orbis arctici cataractis" [Arctic habitat in the entire world cataracts] (Linnaeus, 1758).

Comments: This subfamily contains three genera, Margaritifera, Cumberlandia and Pseudunio. Species of Cumberlandia and Margaritifera have thin to medium thick, elongated shells, while Pseudunio has thick shells and well-developed teeth. All have a shallow open umbo cavity.

Table 8

The most probable ancestral areas of the primary clades within Margaritiferidae inferred from three different statistical modeling approaches. High support values (probability $\geq 70 \%$ ) are highlighted in bold. "Mediterranean + Eastern North America.

\begin{tabular}{|c|c|c|c|c|c|c|}
\hline \multirow[t]{2}{*}{ Clades } & \multirow[t]{2}{*}{ Ancestral areas } & \multirow[t]{2}{*}{ Biogeographic events } & \multicolumn{4}{|c|}{ Probability of ancestral areas (\%) } \\
\hline & & & S-DIVA & DEC & S-DEC & Combined results \\
\hline Margaritiferidae & E. Asia + Mediterranean & Dispersal & 58.3 & 53.3 & 53.4 & 55.0 \\
\hline Gibbosulinae (Gibbosula) & E. Asia & Dispersal & 100.0 & 67.6 & 68.2 & 78.6 \\
\hline G. laosensis - G. crassa & E. Asia + SE. Asia & Vicariance & 100.0 & 71.2 & 68.6 & 79.9 \\
\hline Margaritiferinae (Margaritifera + Pseudunio + Cumberlandia) & E. Asia + Mediterranean & Vicariance & 41.7 & 73.4 & 71.0 & 62.0 \\
\hline Margaritifera & E. Asia & Dispersal & 65.0 & 49.1 & 43.1 & 52.4 \\
\hline M. dahurica - M. margaritifera & E. Asia + Europe & Dispersal + Vicariance & 50.0 & 81.4 & 79.9 & 70.4 \\
\hline M. falcata - M. laevis (Pacific clade) & E. Asia + W. North America & Vicariance & 100.0 & 81.4 & 76.7 & 86.0 \\
\hline M. laevis - M. middendorffi & E. Asia & Dispersal & 97.3 & 63.2 & 67.3 & 49.2 \\
\hline M. middendorffi - M. hembeli & E. Asia + W. North America & Dispersal + Vicariance & 33.3 & 66.0 & 63.8 & 54.4 \\
\hline M. hembeli - M. marrianae & W. North America + E. North America & Dispersal + Extinction & 33.3 & 40.5 & 41.9 & 38.2 \\
\hline Pseudunio + Cumberlandia & Mediterranean & Dispersal + Vicariance & $100.0^{*}$ & 64.6 & 70.5 & 45.0 \\
\hline Pseudunio & Mediterranean & Intra-area radiation & 100.0 & 100.0 & 99.7 & 99.9 \\
\hline$P$. auricularius $-P$. homsensis & Mediterranean & Intra-area radiation & 100.0 & 100.0 & 100.0 & 100.0 \\
\hline
\end{tabular}



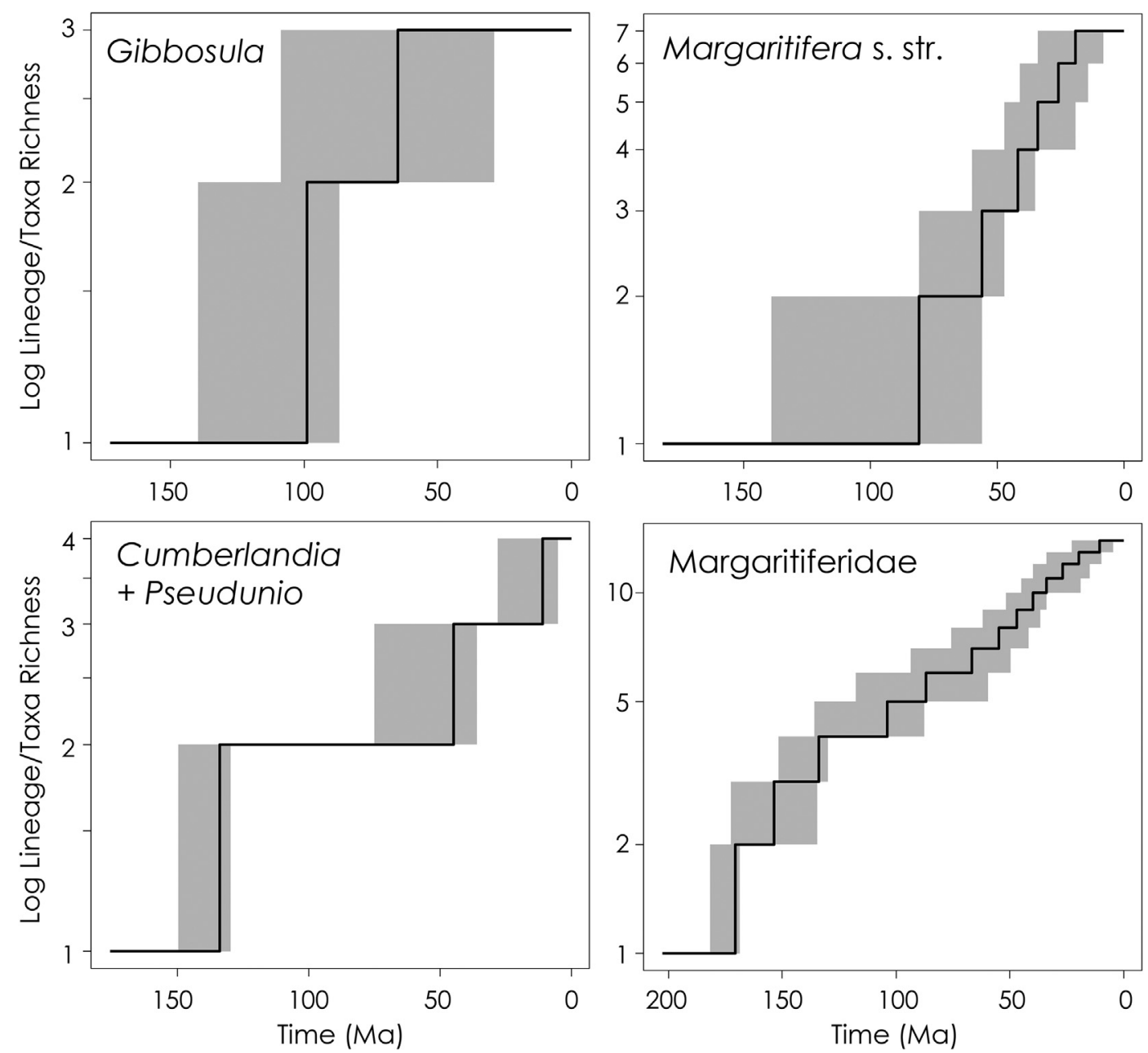

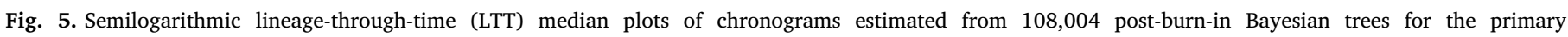
Margaritiferidae clades, including Gibbosula, Cumberlandia + Pseudunio, Margaritifera, and the entire family. The gray filling indicates 95\% confidence intervals.

Table 9

Margaritiferidae systematics and taxonomy.

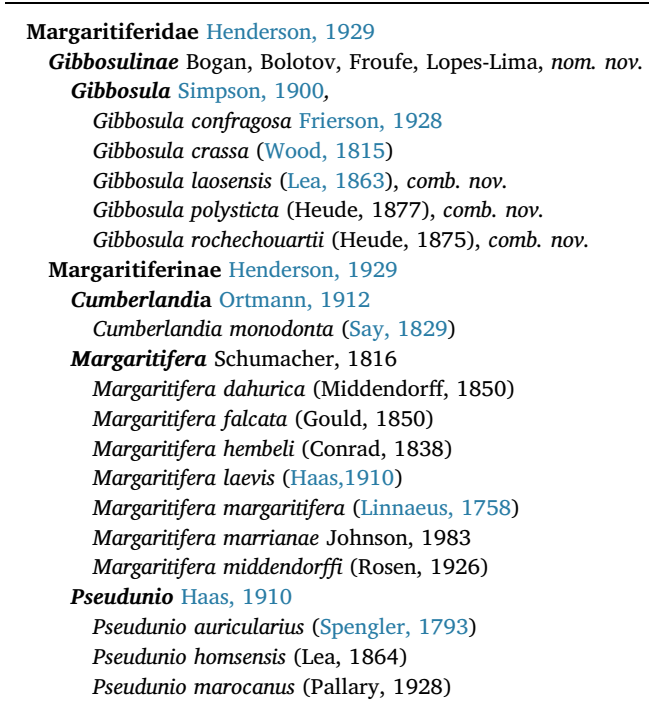

The three genera use different fish families as hosts.

Diagnosis: Shell shape elongate, with a concave or straight ventral margin. Shell thin to moderately thick or thick, posterior ridge rounded. Shell surface smooth or with plications on the posterior slope and the posterior edge of the shell disk. Umbo sculpture is listed as concentric bars but usually eroded. Umbo pocket shallow and open (Fig. 2). Nacre color usually white but may be purple. Lateral teeth usually well-developed but may be reduced; some species have vertical sculpture. Pseudocardinal teeth are peg-like to large (Fig. 2). Fish hosts when known are Salmonidae, Esocidae, Acipenseridae, Blenniidae, Gasterosteidae and Hiodontidae, with host fish families being mutually exclusive to each margaritiferine genus.

Distribution: This subfamily is Holarctic in distribution including North America, Europe, Morocco, Turkey, Syria and Lebanon, China, Japan and eastern Russia (Fig. 6).

Cumberlandia Ortmann, 1912

Type species: Unio monodonta Say, 1829

Type locality: "at the falls of the Ohio, on the rocky flats which are exposed in a low state of the water" (Say, 1829).

Type specimen: The type specimen of Unio monodonta appears to be lost (Watters et al., 2009).

Comments: This large, arcuate shell is distinctive in shape, being very thin shelled and living in fast water usually under large flat rocks. It has been recognized as different from the typical Margaritifera and based on the gill structure, Heard and Guckert (1971) erected a subfamily for this genus.

Diagnosis: Shell shape elongate usually with a convex ventral margin, shell is thin, shell surface is smooth except for growth arrest line, posterior ridge rounded. Lateral teeth reduced to a slight rounded ridge. Pseudocardinal teeth are reduced (Fig. 2). Umbo cavity open and shallow (Fig. 2). Interlamellar gill connections were described as 


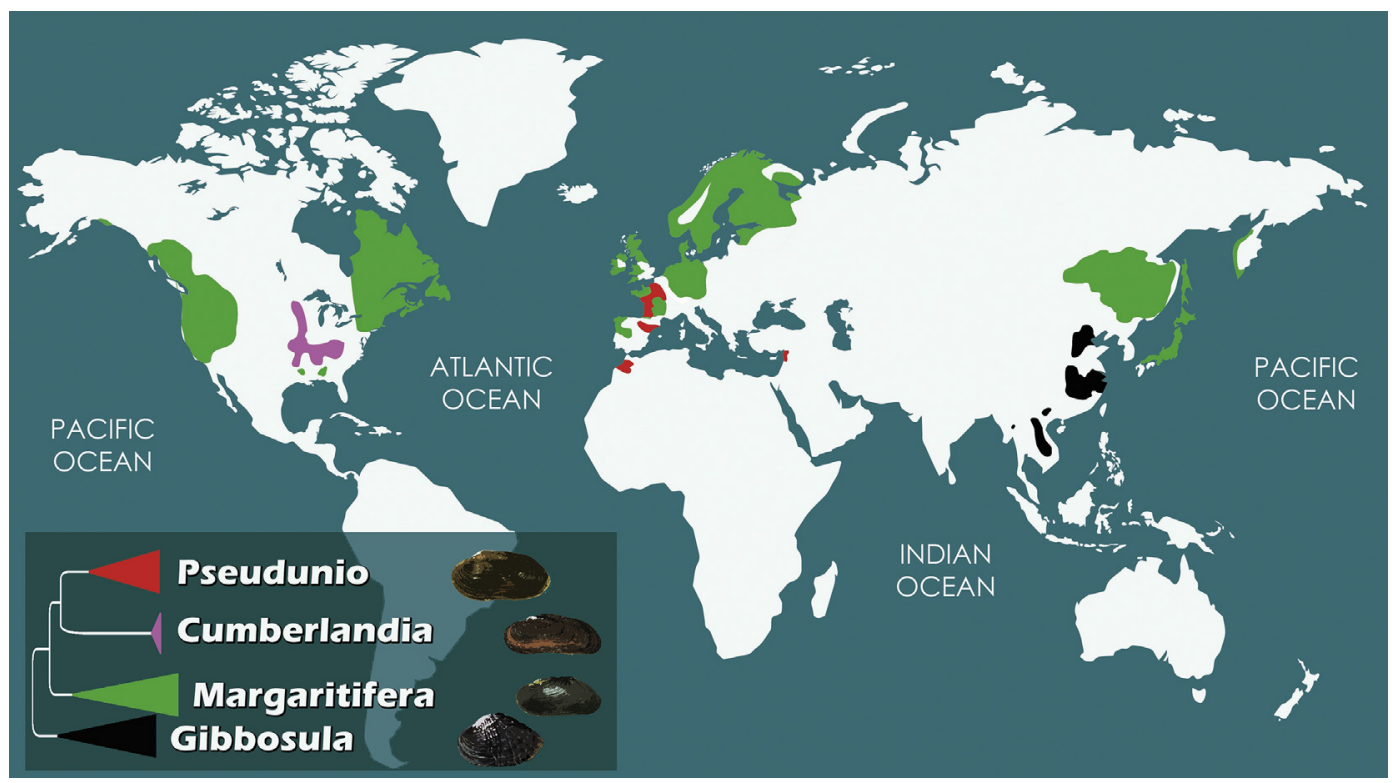

Fig. 6. Distribution map of the Margaritiferidae.

"scattered and in interrupted rows, but developed as continuous septa which run obliquely forward" (Heard and Guckert, 1970). Fish hosts are Hiodontidae.

Distribution: "Cumberlandia monodonta occurs in the Mississippi Basin from southern Minnesota and Wisconsin south to the Ouachita River drainage in south-central Arkansas, and in the Ohio River drainage from Ohio and West Virginia downstream to the mouth of the Ohio River, including some tributaries" such as the Tennessee and Cumberland River drainages (Williams et al., 2008) (Fig. 6).

Margaritifera Schumacher, 1816

Type species Mya margaritifera Linnaeus, 1758

Type locality: "Habitat in totius orbis arctici cataractis" [Arctic habitat in the entire world cataracts]. (Linnaeus, 1758).

Type specimens: There exists a specimen in the Linnean Society of London, Box No. LSL 22, Dance label image Ref. G-M 00101251. Dance was uncertain this was a Linnean specimen, so the listing by Graf and Cumming (2018) may be invalid. There are two additional lots in the Linnean Collection, Uppsala University, Museum of Evolution, Zoology Section (Uppsala University, 1999) which are potentially part of the syntype series (UUZM, 2018).

Comments: Margaritifera is the most widespread genus within the family with a Pacific, Atlantic and central Eurasian distribution. Since Bolotov et al. (2016), the Japanese endemic M. togakushiensis (Kondo and Kobayashi, 2005) has been considered a synonym of M. middendorffi based on morphology and phylogenetic data.

Diagnosis: Shell shape elongate, usually with concave ventral margin. Shell is thin to moderately thick. Posterior ridge rounded. Shell surface smooth except for growth arrest lines. Lateral teeth are distinct and peg-like. Pseudocardinal teeth vary from well-developed to reduced (Fig. 2). Umbo cavity shallow and open (Fig. 2). Nacre color typically white but purple in M. falcata and also in some M. laevis individuals. Host fish are species of the Salmonidae or Esocidae for two species restricted to the Gulf Coast of the United States- (Table 4).

Distribution: The genus Margaritifera is widespread across North America, Western Europe, China, Japan and eastern Russia (Fig. 6).

Pseudunio Haas, 1910

Type species: Unio sinuata Lamarck, 1819 = Unio auricularius Spengler, 1793

Type locality: "Habite dans le Rhin, la Loire, et les autres grandes rivières du continent européen tempéré et austral" [Lives in the Rhine, the Loire and other great rivers of continental Europe] (Lamarck,
1819).

Type specimen: the Mollusk Collection, Muséum d'histoire naturelle, Genève contains one valid syntype of Unio sinuata Lamarck, 1819 MHNG-MOLL-50572 and 3 possible syntypes MHNG-MOLL-50573. Lamarck had only three specimens in total so at least one of these specimens is not a valid type. Dr. Tardy noted the specimens in lot 50573 measured 104 to $117 \mathrm{~mm}$ while Lamarck listed a range of size from 140 to $145 \mathrm{~mm}$ (Tardy, Pers. Comm.). The type of Unio auricularius was first listed and figured by Lister (1685) and is pre-Linnean. Spengler (1793) validated this species. There is a lectotype in lot ZMUC Biv-315 (Knudsen et al., 2003). [Zoological Museum, University of Copenhagen, Copenhagen, Denmark].

Comments: Placement of the three species here assigned to Pseudunio have often been assigned to Margaritifera. However, in the phylogeny presented herein, they form a separate clade from Margaritifera, using a different suite of host fish families.

Diagnosis: Shell shape elongate oval. Shells thick. Posterior ridge rounded. Umbo sculpture is concentric bars. Posterior slope smooth. Shell surface is smooth. Lateral teeth are well developed and most have vertical striations. Pseudocardinal teeth are large and well developed (Fig. 2). Umbo cavity open and shallow (Fig. 2). Fish hosts include species of the Acipenseridae, Blenniidae and Gasterosteidae (Table 4).

Distribution: Species assigned to Pseudunio presently occur in rivers in northern Morocco, the Iberian Peninsula, France, southern Turkey, Syria, Lebanon, and formerly part of England, Italy, Germany and the Netherlands (Fig. 6).

Subfamily Gibbosulinae Bogan, Bolotov, Froufe and Lopes-Lima, new subfamily

Type genus: Gibbosula Simpson, 1900

Type species: Mya crassa Wood, 1815

Type locality: unknown (Wood, 1815); but listed as China, freshwater (Wood, 1825)

Comments: All the taxa included in this subfamily clade except for G. laosensis were historically included in the Unionidae. The only previous reference recognizing that Gibbosula belonged in the Margaritiferidae was by Morrison (1975). Transferring these four taxa from the Unionidae to the Margaritiferidae has changed our understanding of the range in morphological characteristics (including shell shape and anatomy) within this family.

Diagnosis: Shell shape ranges from elongate to rectangular or oval. Shell moderately thick to thick. Posterior ridge rounded to rather sharp. 
Shell surface is smooth with growth arrest rings or with the posterior slope marked with heavy plications and the disk of the shell covered with pustules or w-shaped nodules. Umbo sculpture is unknown. Lateral teeth well developed with vertical sculpture. Pseudocardinal teeth well developed and large (Fig. 2). Umbo pocket deep and compressed (Fig. 2) and one species with the pocket shallow and open. Nacre color is white to some with peach color. Fish hosts for this subfamily are unknown (Table 6).

Distribution: Species assigned to Gibbosula occur or used to occur in the upper Mekong River basin in Thailand, Laos, Vietnam, the Bang River in the Pearl River basin of Vietnam, the middle Sittaung River basin in Myanmar, the Yangtze River basin of southern China and one species from North China (Fig. 6).

Gibbosula Simpson, 1900

Type species: Mya crassa Wood, 1815

Type locality: unknown (Wood, 1815); but listed as China, freshwater (Wood, 1825:12)

Type specimens: Mya crassa types are unknown; Unio (Quadrula) mansuyi Dautzenberg \& Fischer, 1908, a junior synonym, lectotype MNHN-MP-0136 here designated.

Comments: Gibbosula now contains five species, is restricted to Southeast Asia and northeast China. Margaritanopsis laosensis is included in Gibbosula, but conchologically resembles Margaritifera and Cumberlandia with a thin, elongate smooth shell rather than the thick rectangular or oval sculptured shells of the other species assigned to this genus. As Gibbosula nanningensis Qian, Fang and He, 2015, does not conform to the diagnosis of Gibbosula and has simple papillae and not arborescent papillae in the incurrent aperture, it is here transferred to the genus Lamprotula, Unionidae.

Diagnosis: Shell shape varies from rectangular, oval to elongate in G. laosensis. Ventral margin varies from concave in G. laosensis to rounded or convex. Shell thickness ranges from medium-thick in $G$. laosensis to thick. Posterior ridge varies from rounded especially in $G$. laosensis to rather sharp. Umbo sculpture is unknown. Posterior slope has plications but is smooth in G. laosensis. Shell surface is smooth, with plications or covered with pustules of various shapes. Lateral teeth are typically well developed except for the reduced teeth in G. laosensis and have vertical striations. Pseudocardinal teeth are usually large and well developed (Fig. 2), except in G. laosensis where they are peg-like. Umbo cavity deep and compressed (Fig. 2) or open and shallow as in G. laosensis. Nacre color is typically white. Fish hosts are unknown (Table 4).

Distribution: Species assigned to Gibbosula occur in rivers of northern Thailand, Laos, central Myanmar, western Vietnam, northern Vietnam in the headwaters of Pearl River system, tributaries of the Yangtze River basin in southern China, and north China (Fig. 6).

\subsection{Origin and diversification of the Margaritiferidae}

In this study, we provide an updated fossil-calibrated phylogeny of the Margaritiferidae, which includes almost all known members of the family, with exception of $G$. confragosa and $G$. polysticta. These new results suggest that East Asia was the most likely place of origin of the Margaritiferidae. Although the statistical biogeographic models assume that the crown group of the family was widely distributed across the East Laurasia (East Asia + Mediterranean), the fossil evidence shows an East Asian origin for both the stem and the crown group (e.g., Chen, 1984; Jingshan et al., 1993; Ma, 1994, 1996; Jiang et al., 2005; Pan and Sha, 2009; Fang et al., 2009; Yao et al., 2011), i.e., the region of the Yangtze Plate and the adjoining complex of small terranes that formed the present Tibetan Plateau (Van Damme et al., 2015). Additionally, $\dagger$ Shifangella margaritiferiformis Liu \& Luo, 1981 from the Late Triassic deposits of China (Fang et al., 2009) is here proposed as a fossil member of the crown group of Margaritiferidae + Unionidae, most likely representing a separate ancestral family (Supplementary Tables 3 and 4). This agrees with Graf et al. (2015) and Skawina and Dzik (2011), who suggested that pre-Jurassic freshwater bivalves may represent the stem- groups of modern unionoid clades. Bolotov et al. (2017a) showed that the Unionidae most likely originated in East and Southeast Asia, which is consistent with the hypothesis of an Asian origin for both families.

With respect to combined results of our fossil-calibrated and biogeographic modeling, we suggest that the Margaritiferidae family originated in East Asia (Figs. 3 and 4) in the mid-Jurassic, most likely simultaneously with the Unionidae (Bolotov et al., 2017a). We advance that $\uparrow$ Palaeomargaritifera guangyuanensis $\mathrm{Ma}, 1984$ comb. res. from the Middle Jurassic deposits of Sichuan is the earliest known fossil member of the family (Supplementary Tables 3 and 4). This dating is not consistent with the three earlier fossil-calibrated models (Bolotov et al., 2016; Araujo et al., 2017; Huang et al., 2017). Bolotov et al. (2016) placed the origin of Margaritiferidae in the mid-Cretaceous but did not use any fossil calibrations for the deep nodes, which led to a possible underestimation of the family age. In contrast, Araujo et al. (2017) suggested that the family originated in the Late Triassic based on the age of $\dagger$ Shifangella, which is actually the most probable MRCA of Margaritiferidae and Unionidae (Supplementary Tables 3 and 4). Huang et al. (2017) assigned †Shifangella as a stem calibration for the Margaritiferidae and placed the origin of the family crown group in the Late Cretaceous that is close to the dating of Bolotov et al. (2016).

The divergence between Gibbosulinae and Margaritiferinae in the Late Jurassic represented the earliest split within the Margaritiferidae. The Gibbosulinae, a local clade of East Asian origin, diversified during the Late Cretaceous possibly via connections between the paleo-river systems of East and Southeast Asia. We suggest that $\uparrow$ Gibbosula tibetica (Gu, 1976) comb. nov. from the Late Cretaceous deposits of the Tibetan Plateau could be considered the earliest known fossil member of the Gibbosulinae (Supplementary Tables 3 and 4). Whilst Bolotov et al. (2016) hypothesized that $G$. laosensis clustered with $C$. monodonta, this was not confirmed in our phylogeny. This discrepancy can be explained by the absence of other members of the Gibbosulinae in the reconstruction by Bolotov et al. (2016). The external resemblance between $G$. laosensis and C. monodonta that was a subject of long-term discussion (Walker, 1910; Smith, 2001; Bolotov et al., 2016) is surely a result of morphological convergence. Interestingly, both clades (Gibbosulinae and Pseudunio + Cumberlandia) include species with narrow, elongated shells ( $G$. laosensis and C. monodonta) as well as broad, rounded shells ( $G$. crassa, G. rochechouartii, $P$. homsensis).

The Margaritiferinae MRCA had a continuous range from East Asia to the Mediterranean Region in the Late Jurassic, which was most likely facilitated by host fish dispersal within a continuous paleo-river system or along the Tethys coastal line (Hou and Li, 2017). The earliest history of this clade is well documented via fossil records from Jurassic deposits of North Africa and Europe (Delvene et al., 2013, 2016; Van Damme et al., 2015). †"Margaritifera" crosthwaitei (Newton, 1909) from the Late Jurassic deposits of Egypt and $\uparrow$ Asturianaia soudanensis (Van Damme \& Bogan, 2015) comb. nov. from the Middle to Late Jurassic deposits of Niger are the earliest fossil members from North Africa that could be assigned to this clade (Van Damme et al., 2015). Fossils identified as "Margaritifera" cf. valdensis (Mantell, 1844) are known from the Late Jurassic deposits of Spain (Delvene et al., 2013, 2016). There are three additional Late Jurassic margaritiferid species that were recently described from Spain: $\uparrow$ Asturianaia colunghensis Delvene, Munt, Piñuela \& García-Ramos, 2016, †A. lastrensis Delvene, Munt, Piñuela \& García-Ramos, 2016 and †"Margaritifera" lagriega Delvene, Munt, Piñuela \& García-Ramos, 2016 (Delvene et al., 2016).

The MRCA of Pseudunio + Cumberlandia clade most likely originated in the Mediterranean Region and dispersed to eastern North America with subsequent vicariance event in the Early Cretaceous. $\dagger$ Paraheudeana idubedae (Palacios \& Sánchez, 1885) from the Early Cretaceous deposits of Spain appears to be the earliest known member of the crown group of this clade (Supplementary Tables 3 and 4). The evolutionary history of Pseudunio was associated with the intra-Mediterranean radiation from the mid-Eocene to mid-Miocene. Our results support the assumption of Bolotov et al. (2016) that the split between $P$. 
auricularius and $P$. marocanus was well before the Messinian Salinity Crisis (MSC). Additionally, the new model indicates that the split between $P$. auricularius and $P$. homsensis most likely preceded this paleogeographic event. In contrast, the divergence between Unio species in Morocco and Iberia was coincident with the MSC (Froufe et al., 2016). The earliest fossils resembling the extant Cumberlandia are known from the Early Cretaceous deposits in North Africa: $\uparrow C$. rhazensis (Mongin, 1968) comb. nov. and $\dagger C$. saharica (Mongin, 1968) comb. nov. (Van Damme et al., 2015).

Margaritifera is the most widespread and diverse group of recent margaritiferids. This clade most likely originated in East Asia in the Late Cretaceous. The earliest fossils that may belong to this clade are known from the mid-Cretaceous deposits of Mongolia: $\uparrow$ Margaritifera elongata (Martinson, 1982) comb. nov., †M. sainshandensis (Martinson, 1982) comb. nov. and $\uparrow M$. glabra (Kolesnikov, 1956) comb. nov. (Supplementary Table 3). However, the first two species together with nine additional fossil taxa from Mongolia were considered synonyms of $†$ Unio longus (Zhu, 1976) from China (Sha et al., 2006). A detailed discussion of the fossil taxa taxonomy is beyond the scope of the present investigation but it should be mentioned that Sha et al. (2006) provided their revision without studies of the type series of the synonymized species. Our reconstruction of the diversification patterns within this clade is largely congruent with the multiple trans-Beringian exchange model developed by Bolotov et al. $(2015,2016)$ and is supported by numerous fossil records (Supplementary Table 3). In fact, an expanded sampling of species from the 'Pacific' clade (M. falcata, M. laevis, $M$. middendorffi, $M$. hembeli, and M. marrianae) indicates the possibility of an extinction event that closes the gap between East Asian M. middendorffi and its relatives from southeastern North America, i.e., $M$. hembeli and M. marrianae. Previously, Bolotov et al. (2016) suggested that an additional Margaritifera species could be within this gap in accordance with the hypothesis of Taylor (1988) regarding vicariate forms of Margaritiferidae on both sides of the Pacific. However, Taylor's unnamed taxon is actually a morphological form of $M$. falcata, which differs by nacre color (white with salmon spots) but is not genetically different from the typical violet-nacre form (our unpubl. data).

The new fossil-calibrated model also supports the hypothesis that the Mekong and Yangtze unionoid faunas must have developed as independent radiations during the entire Cenozoic (Schneider et al., 2013; Bolotov et al., 2017a,b) because G. laosensis (Mekong River basin) and G. crassa (Pearl River basin) split $\sim 65 \mathrm{Ma}$ ago, and the G. laosensis $+G$. crassa subclade diverged from $G$. rochechouartii (Yangtze) $\sim 103 \mathrm{Ma}$ ago. The two largest paleo-Mekong radiations in the Unionidae most likely originated in the Early Cenozoic (mean age $=51-55 \mathrm{Ma}$ ) or even pre-Cenozoic (mean age $=65-71 \mathrm{Ma}$ ) (Bolotov et al., 2017a,b). These results are in accordance with the concept of long-lived (ancient) rivers, suggesting that several large rivers on Earth may have existed for long-term periods comparable with geological epochs (Bolotov et al., 2017a).

The present results highlight that the placement of several Jurassic and Early Cretaceous margaritiferid species within the genus Margaritifera (e.g., Delvene et al., 2013, 2016; Van Damme et al., 2015) needs to be revised because these taxa most likely represent ancestral fossil lineages that are not directly associated with the crown group of the latter genus despite their morphological similarity. The description of two fossil species from the same deposit on the basis of small conchological differences, a common procedure in systematic paleontology (e.g., Delvene et al., 2016), most likely leads to overestimation of the actual diversity of fossil taxa, e.g. Margaritiferidae, because the sympatric occurrence of several closely related species is an unusual phenomenon. The co-occurrence of $M$. laevis and M. middendorffi in several rivers of Japan, South Kuriles and Sakhalin Island (Bolotov et al., 2015, 2016; Araujo et al., 2017) is the only example of such a secondary sympatry known to date, whereas distribution ranges of the other species reflect a drainage-dependent allopatric speciation model without clear secondary contact zones. This evolutionary pattern suggests a limited number of ancestral fossil lineages not only by the single confirmed extinction event but also by the slow substitution and diversification rates within the family. Modeling results suggest delayed diversification rates in the Margaritiferidae (Fig. 5 and Supplementary Table 5) that are consistent with findings for the Indo-Chinese Unionidae, which also reveal slow diversification rates (Bolotov et al., 2017a). Indeed, the rates in margaritiferids are $\sim 2.5$ times slower compared with the Unionidae (Bolotov et al., 2016). These results may be associated with slower rates of molecular evolution in the Margaritiferidae, which support the hypothesis of a possible link between delayed diversification and slow molecular evolution in freshwater mussels (Bolotov et al., 2017a), although this enigmatic pattern is in need of further investigation.

\section{Conclusions}

The current study supports the increase of extant margaritiferid species to 16 and suggests their division into two subfamilies and four genera. Since a better understanding of phylogenetic diversity is central for determining conservation priorities (Lopes-Lima et al., 2017c, 2018), the results reported here may be important in the definition of future management strategies devoted to conservation of margaritiferid species. The inclusion of G. crassa, G. polysticta, G. rochechouartii, and $G$. confragosa in the Margaritiferidae, confirms the family as the most threatened among unionoids (IUCN, 2018). In fact, the first three mentioned species have a threatened status (IUCN, 2018), while $G$. confragosa has never been evaluated (IUCN, 2018). All four "new" margaritiferids seem to have small distribution ranges and are affected by multiple impacts (IUCN, 2018). Further studies on the Margaritiferidae should include basic ecological and physiological research, collecting data on distribution, abundance, habitat preferences, hostfish identification and reproductive cycles, as well as a phylogenomics approach to complement the current phylogenetic evaluation. Finally, a complete revision of numerous fossil margaritiferid taxa is necessary for the future development of reliable phylogenetic, phylogenomic and biogeographic reconstructions.

\section{Acknowledgments}

The authors would like to thank the editor Dr. Perez-Losada and two anonymous reviewers for their valuable suggestions and comments. M. Caballer MNHN e-RECOLNAT (ANR-11-INBS-0004) and Ms. Virginie Heros, Mollusks, Museum national d'Histoire Naturelle, Paris are acknowledged for the photographs of the types of Unio mansuyi, Unio rochechouartii, and Unio affinis used in this paper and their assistance with specimens in their collection. Ms. Krasimira (Kasey) Seizova, Drexel University Co-op student working in the Malacology Department, Academy of Natural Sciences of Drexel University, Philadelphia took the photographs of the type specimen of Gibbosula confragosa. These pictures were taken for the ANSP type project and used with the permission of Dr. Gary Rosenberg. Pictures of the NCSM specimen of Gibbosula crassa were taken by Ms. Raquel Fagundo and Ms. Joanna Cox; those of the Margaritiferid hinge plates were taken by Macauley Whiting, all in the Non-Molluscan Invertebrate Unit, North Carolina Museum of Natural Sciences, Raleigh, NC with permission of Dr. Bronwyn Williams. Jeffrey T. Garner, Florence, Alabama provided assistance with the USNM ledgers. He Jing, Shell Discoveries and ConchBooks are acknowledged for the permission to reproduce the figures from Qian et al. 2015 for the description of Gibbosula nanningensis.

This work was supported by FCT - Foundation for Science and Technology, Project 3599 - Promote the Scientific Production and Technological Development and Thematic 3599-PPCDT by FEDER as part of the project FRESHCO: Multiple implications of invasive species on Freshwater Mussel co-extinction processes (contract: PTDC/ AGRFOR/1627/2014). FCT also supported MLL (SFRH/BD/115728/ 
2016) and EF (SFRH/BPD/108445/2015). The Russian Ministry of Education and Science (project no. 6.2343.2017/4.6), the Federal Agency for Scientific Organizations (project no. 0409-2015-0143), the Presidium of the Russian Academy of Sciences (scientific program no. 52), and the Russian Foundation for Basic Research, RFBR (project no. 17-45-290066) supported INB, MYG, AVK, and IVV. The Nagao Natural Environment Foundation (NEF) supported for VTD research project "The study of Unionoida biodiversity and conservation status in Bang and Ky Cung River basins in Northeast Vietnam".

\section{Appendix A. Supplementary material}

Supplementary data associated with this article can be found, in the online version, at https://doi.org/10.1016/j.ympev.2018.04.041.

\section{References}

Araujo, R., Schneider, S., Roe, K.J., Erpenbeck, D., Machordom, A., 2017. The origin and phylogeny of Margaritiferidae (Bivalvia, Unionoida): a synthesis of molecular and fossil data. Zool. Scr. 46, 289-307.

Bapst, D.W., 2012. Paleotree: an R package for paleontological and phylogenetic analyses of evolution. Methods Ecol. Evol. 3, 803-807.

Bernt, M., Donath, A., Jühling, F., Externbrink, F., Florentz, C., Fritzsch, G., Pütz, J., Middendorf, M., Stadler, P.F., 2013. MITOS: improved de novo metazoan mitochondrial genome annotation. Mol. Phylogenet. Evol. 69, 313-319. http://dx.doi. org/10.1016/j.ympev.2012.08.023.

Bogan, A.E., 2008. Global diversity of freshwater mussels (Mollusca, Bivalvia) in freshwater. Hydrobiologia 595, 139-147. http://dx.doi.org/10.1007/s10750-007-9011-7.

Bogan, A.E., 2015. Determining the date of publication for Contradens Haas and Uniandra Haas (Bivalvia: Unionidae). Nautilus 129, 175-178.

Bogan, A.E., Do, V.T., 2016. Fieldtrip to Northern Vietnam, 2016. Ellipsaria 18, 27-29. http://dx.doi.org/10.13140/RG.2.2.30491.87842.

Bogatov, V.V., Prozorova, L.A., Starobogatov, Y.I., 2003. The family Margaritiferidae (Mollusca: Bivalvia) in Russia. Ruthenica 13, 41-52.

Bolotov, I.N., Vikhrev, I., Bespalaya, Y.V., Artamonova, V., Gofarov, M.Y., Kolosova, Y.S., Kondakov, A.V., Makhrov, A., Frolov, A.A., Tumpeesuwan, S., Lyubas, A., Romanis, T., Titova, K., 2014. Ecology and conservation of the endangered Indochinese freshwater pearl mussel, Margaritifera laosensis (Lea, 1863) in the Nam Pe and Nam Long rivers, Northern Laos. Trop. Conserv. Sci. 7, 706-719.

Bolotov, I.N., Bespalaya, Y.V., Vikhrev, I.V., Aksenova, O.V., Aspholm, P.E., Gofarov, M.Y., Klishko, O.K., Kolosova, Y.S., Kondakov, A.V., Lyubas, A.A., Paltser, I.S., Konopleva, E.S., Tumpeesuwan, S., Bolotov, N.N., Voroshilova, I.S., 2015. Taxonomy and distribution of the freshwater pearl mussels (Unionoida: Margaritiferidae) in the Far East of Russia. PLoS ONE 10, e0122408.

Bolotov, I.N., Vikhrev, I.V., Bespalaya, Y.V., Gofarov, M.Y., Kondakov, A.V., Konopleva, E.S., Bolotov, N.N., Lyubas, A.A., 2016. Multi-locus fossil-calibrated phylogeny, biogeography and a subgeneric revision of the Margaritiferidae (Mollusca: Bivalvia: Unionoida). Mol. Phylogenet. Evol. 103, 104-121. http://dx.doi.org/10.1016/j. ympev.2016.07.020.

Bolotov, I.N., Kondakov, A.V., Vikhrev, I.V., Aksenova, O.V., Bespalaya, Y.V., Gofarov, M.Y., Kolosova, Y.S., Konopleva, E.S., Spitsyn, V.M., Tanmuangpak, K., Tumpeesuwan, S., 2017a. Ancient river inference explains exceptional Oriental freshwater mussel radiations. Sci. Reports 7, 2135.

Bolotov, I.N., Vikhrev, I.V., Kondakov, A.V., Konopleva, E.S., Gofarov, M.Yu., Aksenova, O.V., Tumpeesuwan, S., 2017b. New taxa of freshwater mussels (Unionidae) from a species-rich but overlooked evolutionary hotspot in Southeast Asia. Sci. Reports 7, 11573.

Boss, K.J., 1982. Mollusca. In: In: Parker, S.P. (Ed.), Synopsis and Classification of Living Organisms, vol. 1. McGraw Hill Book Co., New York, USA, pp. 945-1166.

Chen, J.-H., 1984. Some Jurassic and Cretaceous non-marine bivalves from Shandong [in Chinese with English summary]. Acta Palaeontol. Sin. 23, 148-154.

Conant, G.C., Wolfe, K.H., 2008. GenomeVx: simple web-based creation of editable circular chromosome maps. Bioinformatics 24, 861-862. http://dx.doi.org/10.1093/ bioinformatics/btm598.

Darriba, D., Taboada, G.L., Doallo, R., Posada, D., 2012. jModelTest 2: more models, new heuristics and parallel computing. Suppl. Mat. Nat. Methods 9, 772. http://dx.doi. org/10.1038/nmeth.2109.

Dautzenberg, P., Fischer, H., 1908. Liste des Molluques récoltés par M. Mansuy en IndoChine et description d'espèces nouvelles II. J. Conchyliol. 56, 169-217.

Delvene, G., Munt, M.C., Piñuela, L., García-Ramos, J.C., 2016. New Unionida (Bivalvia) from the Kimmeridgian (Late Jurassic) of Asturias, Spain, and their palaeobiogeographical implications. Papers Palaeontol. 2, 265-285.

Delvene, G., Munt, M., Royo-Torres, R., Cobos, A., Alcalá, L., 2013. Late Jurassic-Early Cretaceous freshwater bivalves from Turiasaurus riodevensis bearing strata of Teruel (Spain). Spanish J. Palaeontol. 28, 161-172.

Do, V., 2011a. Lamprotula rochechouartii. The IUCN Red List of Threatened Species 2011: e.T166308A6197608. < http://www.iucnredlist.org > (accessed 4 January 2018). doi:10.2305/IUCN.UK.2011-1.RLTS.T166308A6197608.en.

Do, V., 2011b. Lamprotula polysticta. The IUCN Red List of Threatened Species 2011: e. T166277A6194151. < http://www.iucnredlist.org > (accessed 4 January 2018).
doi:10.2305/IUCN.UK.2011-1.RLTS.T166277A6194151.en.

Drummond, A.J., Rambaut, A., 2007. BEAST: Bayesian evolutionary analysis by sampling trees. BMC Evol. Biol. 7, 214.

Drummond, A.J., Ho, S.Y., Phillips, M.J., Rambaut, A., 2006. Relaxed phylogenetics and dating with confidence. PLoS Biol. 4, 699.

Drummond, A.J., Suchard, M.A., Xie, D., Rambaut, A., 2012. Bayesian phylogenetics with BEAUti and the BEAST 1.7. Mol. Biol. Evol. 29, 1969-1973.

Fang, Z.J., Chen, J.H., Chen, C.Z., Sha, J.G., Lan, X., Wen, S.X., 2009. Supraspecific taxa of the Bivalvia first named, described, and published in China (1927-2007). Univ. Kansas Paleontol. Contrib. (New Ser.) 17, 1-157.

Frierson, L., 1927. A Classified and Annotated Check List of the North American naiades. Baylor University Press, Waco, TX, USA.

Frierson, L.S., 1928. Gibbosula confragosa, a new unionid from China. Proc. Acad. Nat. Sci. Philadelphia 80, 147.

Froufe, E., Gonçalves, D.V., Teixeira, A., Sousa, R., Varandas, S., Ghamizi, M., Zieritz, A., Lopes-Lima, M., 2016. Who lives where? Molecular and morphometric analyses clarify which Unio species (Unionida, Mollusca) inhabit the southwestern Palearctic region. Org. Divers. Evol. 16, 597-611.

Gan, H., Schultz, M.B., Austin, C.M., 2014. Integrated shotgun sequencing and bioinformatics pipeline allows ultra-fast mitogenome recovery and confirms substantial gene rearrangements in Australian freshwater crayfishes. BMC Evol. Biol. 14, 19. http:// dx.doi.org/10.1186/1471-2148-14-19.

Giribet, G., Wheeler, W., 2002. On bivalve phylogeny: a high-level analysis of the Bivalvia (Mollusca) based on combined morphology and DNA sequence data. Invertebr. Biol. 121, 271-324. http://dx.doi.org/10.1111/j.1744-7410.2002.tb00132.x.

Graf, D.L., Cummings, K.S., 2006. Palaeoheterodont diversity (Mollusca: Trigonioida + Unionoida): what we know and what we wish we knew about freshwater mussel evolution. Zool. J. Linn. Soc. 148, 343-394. http://dx.doi.org/10.1111/j.1096-3642. 2006.00259.x.

Graf, D.L., Cummings, K.S., 2007. Review of the systematics and global diversity of freshwater mussel species (Bivalvia: Unionoida). J. Molluscan Stud. 73, 291-314. http://dx.doi.org/10.1093/mollus/eym029.

Graf, D.L., Cummings, K.S., 2018. The MUSSEL Project Database. < http://musselproject. uwsp.edu/db/ > (accessed 4 January 2018).

Graf, D.L., Jones, H., Geneva, A.J., Pfeiffer, J.M., Klunzinger, M.W., 2015. Molecular phylogenetic analysis supports a Gondwanan origin of the Hyriidae (Mollusca: Bivalvia: Unionida) and the paraphyly of Australasian taxa. Mol. Phylogenet. Evol. $85,1-9$.

Haag, W.R., 2012. North American Freshwater Mussels. Natural History, Ecology, and Conservation. Cambridge University Press, Cambridge, UK.

Haas, F., 1910a. Pseudunio, neues Genus für Unio sinuatus Lam. Nachrichtsblatt der Dtsch. Malakozool. Gesellschaft 42, 181-183.

Haas, F., 1910b-1920. Die Unioniden. Neubearbeitung und Fortsetzung der Küsterschen und Clessinschen Monographien von Unio und Anodonta. In: Küster, H.C. (Ed.), Systematisches Conchylien-Cabinet von Martini und Chemnitz 9, pp. 1-344.

Haas, F., 1969a. Superfamilia Unionacea. Das Tierrich, 88. Walter de Gruyter, Berlin.

Haas, F., 1969b. Superfamily Unionacea. In: Moore, R.C. (Ed.), Treatise on Invertebrate Paleontology Part N, Volume 1, Mollusca 6. Bivalvia. Geological Society of America. The University of Kansas, pp. N411-N470.

He, J., Zhuang, Z., 2013. The Freshwater Bivalves of China. Conchbooks, Harxheim, Germany.

Heard, W.H., Guckert, R.H., 1970. A re-evaluation of the Recent Unionacea (Pelecypoda) of North America. Malacologia 10, 333-355.

Henderson, J., 1929. Non-marine Mollusca of Oregon and Washington. Univ. Color. Stud. 17, 47-190.

Henderson, J., 1935. Fossil non-marine mollusca of North America. Geol. Soc. Am. Spec. Pap. 3, 1-290. http://dx.doi.org/10.1130/SPE3-p1.

Hou, Z., Li, S., 2017. Tethyan changes shaped aquatic diversification. Biol. Rev. http://dx. doi.org/10.1111/brv.12376.

Huang, X.-C., Wu, R.-W., An, C.-T., Xie, G.-L., Su, J.-H., Ouyang, S., Zhou, C.-H., Wu, X.P., 2017. Reclassification of Lamprotula rochechouartii as Margaritifera rochechouartii comb. nov. (Bivalvia: Margaritiferidae) revealed by time-calibrated multilocus phylogenetic analyses and mitochondrial phylogenomics of Unionoida. Mol. Phylogenet. Evol. http://doi.org/10.1016/j.ympev.2017.12.017.

Huff, S.W., Campbell, D., Gustafson, D.L., Lydeard, C., Altaba, C.R., Giribet, G., 2004. Investigations into the phylogenetic relationships of freshwater pearl mussels (Bivalvia: Margaritiferidae) based on molecular data: implications for their taxonomy and biogeography. J. Molluscan Stud. 70, 379-388. http://dx.doi.org/10.1093/ mollus/70.4.379.

IUCN, 2018. The IUCN Red List of Threatened Species. Version 2017-2. < http://www. iucnredlist.org > (accessed 4 January 2018).

Jiang, B., Cai, H., Chen, S., 2005. Some Middle Jurassic bivalves from the Kuche Depression of the Tarim Basin, northwestern China. Acta Palaeontol. Sin. 44, 296-305.

Jingshan, Y., Mizuno, A., Lixin, W., 1993. The Jurassic system in the Qinshui Basin, Shanxi Province, with notes on the bivalve province of North China. Palaeogeogr. Palaeoclimatol. Palaeoecol. 105, 157-170.

Katoh, K., Standley, D.M., 2013. MAFFT Multiple Sequence Alignment Software Version 7: Improvements in Performance and Usability. Mol. Biol. Evol. 30, 772-780. http:// dx.doi.org/10.1093/molbev/mst010.

Lamarck, J.B.P.A., 1819. Les nayades. In: Histoire naturelle des Animaux sans Vertébres, vol. 6. Paris, pp. 67-100.

Laslett, D., Canbäck, B., 2008. ARWEN: a program to detect tRNA genes in metazoan mitochondrial nucleotide sequences. Bioinformatics 24, 172-175. http://dx.doi.org/ 10.1093/bioinformatics/btm573.

Lea, I., 1852. Descriptions of new species of the family Unionidae. Trans. Am. Philos. Soc. 
$10,253-294$.

Lea, I., 1863. Description of a new species of Unio and a Monocondylaea. Proc. Acad. Nat. Sci. Philadelphia 15, 190

Linnaeus, C., 1758. Systema Naturae. Edition X. (Systema naturae per regna tria naturae, secundum classes, ordines, genera, species cum characteribus, differentiis, synonymis, locis. Tomus I. Edtio decima, reformata.) Holmiae.

Lopes-Lima, M., Froufe, E., Do, V.T., Ghamizi, M., Mock, K.E., Kebapçı, Ü., Klishko, O., Kovitvadhi, S., Kovitvadhi, U., Paulo, O.S., Pfeiffer III, J.M., Raley, M., Riccardi, N., Sereflişan, H., Sousa, R., Teixeira, A., Varandas, S., Wu, X., Zanatta, D.T., Zieritz, A., Bogan, A.E., 2017a. Phylogeny of the most species-rich freshwater bivalve family (Bivalvia: Unionida: Unionidae): defining modern subfamilies and tribes. Mol. Phylogenet. Evol. 106, 174-191. http://dx.doi.org/10.1016/j.ympev.2016.08.021.

Lopes-Lima, M., Fonseca, M.M., Aldridge, D.C., Bogan, A.E., Gan, H.M., Ghamizi, M., Sousa, R., Teixeira, A., Varandas, S., Zanatta, D., Zieritz, A., Froufe, E., 2017b. The first Margaritiferidae male (M-type) mitogenome: mitochondrial gene order as a potential character for determining higher-order phylogeny within Unionida (Bivalvia). J. Molluscan Stud. 83, 249-252. http://dx.doi.org/10.1093/mollus/ eyx009.

Lopes-Lima, M., Sousa, R., Geist, J., Aldridge, D.C., Araujo, R., Bergengren, J., Bespalaya, Y., Bódis, E., Burlakova, L., Van Damme, D., Douda, K., Froufe, E., Georgiev, D., Gumpinger, C., Karatayev, A., Kebapçi, Ü., Killeen, I., Lajtner, J., Larsen, B.M., Lauceri, R., Legakis, A., Lois, S., Lundberg, S., Moorkens, E., Motte, G., Nagel, K.-O., Ondina, P., Outeiro, A., Paunovic, M., Prié, V., von Proschwitz, T., Riccardi, N., Rudzīte, M., Rudzītis, M., Scheder, C., Seddon, M., Şereflişan, H., Simić, V., Sokolova, S., Stoeckl, K., Taskinen, J., Teixeira, A., Thielen, F., Trichkova, T., Varandas, S., Vicentini, H., Zajac, K., Zajac, T., Zogaris, S., 2017c. Conservation status of freshwater mussels in Europe: state of the art and future challenges. Biol. Rev. 92, 572-607. http://dx.doi.org/10.1111/brv.12244.

Lopes-Lima, M., Burlakova, L.E., Karatayev, A.Y., Mehler, K., Seddon, M., Sousa, R., 2018. Conservation of freshwater bivalves at the global scale: diversity, threats and research needs. Hydrobiologia. 810, 1-14. http://dx.doi.org/10.1007/s10750-017-3486-7.

Ma, Q., 1994. Nonmarine Cretaceous bivalve assemblages in China. Cretaceous Res. 15, 271-284.

Ma, Q., 1996. Revision of Mesozoic Margaritiferidae in China and their development [In Chinese with English summary]. Acta Palaeontol. Sin. 35, 408-429.

Martinson, G.G., 1982. Late Cretaceous Molluscs of Mongolia. Nauka Publ., Moscow, 82 pp (in Russian).

McMichael, D., Hiscock, I., 1958. A Monograph of the Freshwater Mussels (Mollusca: Pelecypoda) of the Australian Region. Mar. Freshw. Res. 9, 372. http://dx.doi.org/ 10.1071/MF9580372.

Miller, M., Pfeiffer, W., Schwartz, T., 2010. Creating the CIPRES science gateway for inference of large phylogenetic trees. In: Gateway Computing Environments Workshop (GCE). IEEE, pp. 1-8.

Modell, H., 1942. Das natürliche system der Najaden. Arch. Molluskenkd. 74, 161-191. Modell, H., 1949. Das natürliche system der Najaden. 2. Arch. Molluskenkd. 78, 29-46. Modell, V.H., 1957. Die fossilen Najaden Nordamerikas. Arch. Molluskenkd. 86, 183-200. Modell, H., 1964. The natural system of the naiads. 3. Arch. Molluskenkd. 93, 71-126. Morrison, J.P.E., 1975. Relict mussels from two continents. Bull. Am. Malacol. Union 70. Nedeau, E.J., Smith, A.K., Stone, J., Jepsen, S., 2009. Freshwater Mussels of the Pacific Northwest, second ed. The Xerces Society, Portland, Oregon.

Ortmann, A.E., 1910. A new system of the Unionidae. Nautilus 23, 114-120.

Ortmann, A.E., 1911a. The anatomical structure of certain exotic naiades compared with that of the North American forms. Nautilus (Philadelphia) 24, 103-108.

Ortmann, A.E., 1912. Cumberlandia, a new genus of naiades. The Nautilus 26, 13-14.

Ortmann, A.E., 1921. South American naiades: a contribution to the knowledge of the freshwater mussels of South America. Mem. Carnegie Museum 8, 451-670.

Palacios, P., Sánchez, R., 1885. La formación Wealdense en las provincias de Soria y Logroño. Boletín la Com. del Mapa Geológico España 12, 1-32.

Pan, Y.H., Sha, J.G., 2009. Middle Jurassic unionids (non-marine Bivalvia) from the Shiwandashan Basin, southern China, with special emphasis on Cuneopsis Simpson. GFF 131, 183-194.

Paradis, E., 1997. Assessing temporal variations in diversification rates from phylogenies: estimation and hypothesis testing. P. Roy. Soc. Lond. B Bio. 264, 1141-1147.

Paradis, E., 2012. Analysis of Phylogenetics and Evolution with R, second ed. Springer, New York.

Parmalee, P.W., Bogan, A.E., 1998. Freshwater Mussels of Tennessee. University of Tennessee Press, Knoxville, TN, USA.

Pfeiffer III, J.M., Graf, D.L., 2013. Re-analysis confirms the polyphyly of Lamprotula Simpson, 1900 (Bivalvia: Unionidae). J. Molluscan Stud. 79, 249-256. http://dx.doi. org/10.1093/mollus/eyt022.

Pfeiffer III, J.M., Graf, D.L., 2015. Evolution of bilaterally asymmetrical larvae in freshwater mussels (Bivalvia: Unionoida: Unionidae). Zool. J. Linn. Soc. 175, 307-318. http://dx.doi.org/10.1111/zoj.12282.

Popescu, A.A., Huber, K.T., Paradis, E., 2012. APE 3.0: new tools for distance based phylogenetics and evolutionary analysis in R. Bioinformatics 28, 1536-1537.

Prié, V., Bousquet, P., Serena, A., Tabacchi, E., Jourde, P., Adam, B., Deschamps, T., Charneau, M., Tico, T., Bramard, M., Cochet, G., 2010. Newly discovered populations of giant pearl mussel Margaritifera auricularia (Spengler, 1793) (Bivalvia: Margaritiferidae) in south-west France. MalaCo 6, 294-297.

Prié, V., Soler, J., Araujo, R., Cucherat, X., Philippe, L., Patry, N., Adam, B., Legrand, N., Jugé, P., Richard, N., Wantzen, K.M., 2018. Challenging exploration of troubled waters: a decade of surveys of the giant freshwater pearl mussel Margaritifera auricularia in Europe. Hydrobiologia. http://dx.doi.org/10.1007/s10750-017-3456-0.

Prozorova, L.A., Sayenko, E.M., Bogatov, V.V., Wu, M., Liu, Y.Y., 2005. Bivalves of the Yangtze River drainage. Bull. Russ. Far East Malacol. Soc. 9, 46-58.

Pybus, O.G., Harvey, P.H., 2000. Testing macro-evolutionary models using incomplete molecular phylogenies. P. Roy. Soc. Lond. B Bio. 267, 2267-2272.

Qian, Z., Fang, Y., He, J., 2015. Description of two new freshwater mussels from China. Shell Discov. 1, 32-33.

Rambaut, A., Suchard, M., Drummond, A.J., 2014. Tracer v1.6. Available: < http://beast. bio.ed.ac.uk/software/tracer/ > (accessed 4 January 2018).

Ronquist, F., Teslenko, M., van der Mark, P., Ayres, D.L., Darling, A., Höhna, S., Larget, B., Liu, L., Suchard, M.A., Huelsenbeck, J.P., Hohna, S., Larget, B., Liu, L., Suchard, M.A., Huelsenbeck, J.P., 2012. MrBayes 3.2: efficient Bayesian phylogenetic inference and model choice across a large model space. Syst. Biol. 61, 539-542. http://dx.doi.org/ $10.1093 /$ sysbio/sys029.

Say, T., 1829. Descriptions of some new terrestrial and fluviatile shells of North America. The Disseminator of Useful Knowledge; containing hints to the youth of the United States, from the School of Industry, New Harmony, Indiana, USA.

Schneider, S., Prieto, J., 2011. First record of an autochthonous community of fluviatile freshwater molluscs from the Middle/Late Miocene Upper Freshwater Molasse (southern Germany). Arch. Molluskenkd. 140, 1-18.

Schneider, S., Böhme, M., Prieto, J., 2013. Unionidae (Bivalvia; Palaeoheterodonta) from the Palaeogene of northern Vietnam: exploring the origins of the modern East Asian freshwater bivalve fauna. J. Syst. Palaeontol. 11, 337-357.

Sela, I., Ashkenazy, H., Katoh, K., Pupko, T., 2015. GUIDANCE2: accurate detection of unreliable alignment regions accounting for the uncertainty of multiple parameters. Nucl. Acids Res. 43, W7-W14. http://dx.doi.org/10.1093/nar/gkv318.

Sha, J., Lin, L., Chen, S., Matsukawa, M., 2006. Some Lower Cretaceous nonmarine bivalves from fluvio-lacustrine deposits bearing dinosaur fossils in Mongolia and northeast China. Cretaceous Res. 27, 262-278.

Schumacher, C.F., 1815 (1816). Afhandling over conchyliologiske Systemer, og om nogle toskallende Conchylier. Oversigt over det Kongelige Danske Videnskabernes Selskabs Forhandlinger og dets Medlemmers Arbeider i de sidst to Aar.

Sietman, B., Davis, M., Hove, M., Pletta, M., Wagner, T., Marr, S., Secrist, Z., Freeburg, M., Scheunemann, A., Krupp, K., Hagemeyer, E., Franzen, A., Swanson, C., Sampson, A., 2017. Cumberlandia monodonta - Host Enigma Resolved. Ellipsaria 19, 18-20.

Simpson, C.T., 1900. Synopsis of the Naiades: or pearly fresh-water mussels. Proc. United States Natl. Museum 22, 501-1044.

Simpson, C.T., 1914. A Descriptive catalogue of the Naiades, or pearly fresh-water mussels. Parts I-III. Bryant Walker, Detroit, Michigan.

Skawina, A., Dzik, J., 2011. Umbonal musculature and relationships of the Late Triassic filibranch unionoid bivalves. Zool. J. Linn. Soc. 163, 863-883.

Smith, D.G., 2001. Systematics and Distribution of the Recent Margaritiferidae. In: Bauer, G., Wächtler, K. (Eds.), Ecology and Evolution of the Freshwater Mussels Unionoida, Ecological Studies. Springer Berlin Heidelberg, Berlin, Heidelberg, Germany, pp. 33-49. http://doi.org/10.1007/978-3-642-56869-5.

Sousa, R., Varandas, S., Teixeira, A., Ghamizi, M., Froufe, E., Lopes-Lima, M., 2016. Pearl mussels (Margaritifera marocana) in Morocco: Conservation status of the rarest bivalve in African fresh waters. Sci. Total Environ. 547, 405-412. http://dx.doi.org/10. 1016/j.scitotenv.2016.01.003.

Sousa, R., Teixeira, A., Santos, A., Benaissa, H., Varandas, S., Ghamizi, M., Prié, V., Froufe, E., Lopes-Lima, M., 2018. Oued Bouhlou: a new hope for the Moroccan pearl mussel. Aquat. Conserv. Mar. Freshw. Ecosyst. http://dx.doi.org/10.1002/aqc.2825.

Spengler, L., 1793. Beskrivelse over et nyt Slægt af de toskallede Konkylier, forhen af mig kaldet Chaena, saa og over det Linnéiske Slægt Mya, hvilket nøiere bestemmes, og inddeles i tvende Slægter. Skrivter af Natur-historie-Selskabet 3, 16-69.

Stamatakis, A., 2014. RAxML version 8: a tool for phylogenetic analysis and post-analysis of large phylogenies. Bioinformatics 30, 1312-1313. http://dx.doi.org/10.1093/ bioinformatics/btu033.

Starobogatov, Y.I., 1970. Fauna Mollyuskov i Zoogeograficheskoe Raionirovanie Kontinental'nykh Vodoemov Zemnogo Shara [Mollusk Fauna and Zoogeographical Partitioning of Continental Water Reservoirs of the World]. Nauka, Leningrad, Russia.

Starobogatov, Y.I., 1995. The pearly freshwater mussels (Mollusca, Unionoida, Margaritiferidae) of Russia. In: Proceedings of the Ninth International Colloquium of the European Invertebrate Survey, Helsinki, Finland, 3-4 September 1993. WWF [World Wildlife Fund] Finland, Helsinki, Finland, pp. 109-112.

Tamura, K., Stecher, G., Peterson, D., Filipski, A., Kumar, S., 2013. MEGA6: molecular evolutionary genetics analysis version 6.0. Mol. Biol. Evol. 30, 2725-2729. http://dx. doi.org/10.1093/molbev/mst197.

Taylor, D.W., 1988. Aspects of freshwater mollusc ecological biogeography. Palaeogeogr. Palaeoclimatol. Palaeoecol. 62, 511-576.

Thiele, J., 1934. Handbuch der systematischen Weichtierkunde. Gustav Fischer, Jena, Germany.

UUZM, 2018. Catalogue of type specimens. 4. Linnaean specimens. Available at: < http://www.evolutionsmuseet.uu.se/samling/UUZM04_Linnaeus.pdf $>$ (accessed 4 January 2018).

Van Damme, D., Bogan, A.E., Dierick, M., 2015. A revision of the Mesozoic naiads (Unionoida) of Africa and the biogeographic implications. Earth-Sci. Rev. 147, 141-200. http://dx.doi.org/10.1016/j.earscirev.2015.04.011.

Vikhrev, I.V., Bolotov, I.N., Altun, A., Gofarov, M.Y., Dvoryankin, G.A., Kondakov, A.V., Ozcan, T., Ozcan, G., 2017. The Revenant: rediscovery of Margaritifera homsensis from Orontes drainage with remarks on its taxonomic status and conservation (Bivalvia: Margaritiferidae). Syst. Biodivers. 16, 69-80. http://dx.doi.org/10.1080/14772000. 2017.1343876.

Walker, B., 1910. The distribution of Margaritana margaritifera (Linn.) in North America. J. Mollus. Stud. 9, 126-145.

Watters, G.T., Hoggarth, M.A., Stansbery, D.H., 2009. The Freshwater Mussels of Ohio. Ohio State University Press, Columbus, OH, USA.

Williams, J.D., Bogan, A.E., Garner, J.T., 2008. Freshwater mussels of Alabama and the Mobile Basin in Georgia, Mississippi, and Tennessee. University Alabama Press, 
Tuscaloosa.

Wood, W., 1815. General Conchology: or, a description of shells arranged according to the Linnean system and illustrated with plates drawn and coloured from nature 1 . John Booth, London, UK.

Wood, W., 1825. Index Testaceologicus; or a Catalogue of Shells, British and Foreign, arranged according to the Linnean System; with the Latin and English names, references to authors, and places where found. Printed for W. Wood, 428 Strand, London, UK.

Xia, X., 2017. DAMBE6: New tools for microbial genomics, phylogenetics and molecular evolution. J. Hered. 108, 431-437.

Yao, H., Zhang, R., Duan, Q., Sheng, X., Niu, Z., Wang, J., Zeng, B., Wu, J., 2011. Jurassic rocks, bivalves, and depositional environments of the source area of the Yangtze River, Qinghai Province, western China. Sci. China Earth Sci. 54, 1136-1148.

Yu, Y., Harris, A.J., Blair, C., He, X.J., 2015. RASP (Reconstruct Ancestral State in Phylogenies): a tool for historical biogeography. Mol. Phylogenet. Evol. 87, 46-49.

Zhou, C.-H., Ouyang, S., Wu, X.-P., Li, M., 2007. Phylogeny of the genus Lamprotula Unionidae in China based on mitochondrial DNA sequences of 16S rRNA and ND1 genes. Acta Zool. Sin. 53, 1024-1030.

Zieritz, A., Sartori, A.F., Bogan, A.E., Aldridge, D.C., 2015. Reconstructing the evolution of umbonal sculptures in the Unionida. J. Zool. Syst. Evol. Res. 53, 76-86. http://dx. doi.org/10.1111/jzs.12077.

\section{Further reading}

Agassiz, L., 1846. Nomenclatoris zoologici. Index universalis, continens nomina systematic classium, ordinum, familiarum et generum animalium omnium. Jent et Gassmann, Soloduri, Switzerland.

Bogatov, V.V., Zatravkin, M.N., 1988. New species of the order Unioniformes (Mollusca: Bivalvia) from the south of the Soviet Far East. Tr. Zool. Instituta Akad. Nauk SSSR 187, 155-168 (in Russian).

Brandt, R.A.M., 1974. The non-marine aquatic Mollusca of Thailand. Arch. für Molluskenkd. 105, 1-423.

Conrad, T.A., 1853. A synopsis of the family of Naïades of North America, with notes, and a table of some of the genera and sub-genera of the family, according to their geographical distribution, and descriptions of genera and sub-genera. Proc. Acad. Nat. Sci. Philadelphia 6, 243-269.

Đặng, N.T., Thái, T.B., Phạm, V.M., 1980. Identification of freshwater invertebrates of North Vietnam. In: Bivalvia. Sciences and Technology Publishing Co., Hanoi, Viet Nam, pp. 491-573.

Đăng, N.T., Hồ, T.H., 2018. Freshwater bivalves and snails of Vietnam (Mollusca: Gastropoda, Bivalvia). Publishing House for Science and Technology, Hanoi, Vietnam.

Dillwyn, L.W., 1817. A descriptive catalogue of recent shells, arranged according to the Linnaean method, with particular attention to the synonymy. Printed for John and Arthur Arch, Cornhill, London, UK.

Do, V.T., Tuan, L.Q., Bogan, A.E., 2018. Freshwater mussels (Bivalvia: Unionida) of Vietnam: diversity, distribution and conservation status. Freshw. Moll. Biol. Conserv. 21, 1-18.

Fagot, P., 1893. Histoire malacologique des Pyrénées Françaises et Espagnoles. Bull. Société Ramond 28, 247-262.

Graf, D.L., 2010. Funeral for the Nouvelle École -iana generic names introduced for freshwater mussels (Mollusca: Bivalvia: Unionoida). Proc. Acad. Nat. Sci. Philadelphia 159, 1-23. http://dx.doi.org/10.1635/053.159.0101.

Gray, J.E., 1847. A list of the genera of Recent Mollusca, their synonyma and types. Proc. Zool. Soc. London 15, 129-206.

Heude, P., 1875-1885. Conchyliologie fluviatile de la province de Nanking et de la Chine centrale. Librairie F. Savy, Paris, France.

ICZN, 1957. Opinion 495. Designation under the plenary powers of a type species in harmony with accustomed usage for the nominal genus "Unio" Philipsson, 1788 (Class Pelecypoda) and validation under the same powers of the family-group name "Margaritiferidae" Haas, 1940. Opinions and Declarations Rendered by the International Commission on Zoological Nomenclature 17, 287-322.

ICZN, 1999. International Code of Zoological Nomenclature, fourth ed. International Trust for Zoological Nomenclature, London.

Johnson, R.I., 1973. Heude's molluscan types or Asian land and fresh water mollusks, mostly from the People's Republic of China, described by P.M. Heude. Special Occasional Publications No. 1. Department of Mollusks, Museum of Comparative Zoology, Harvard University, Cambridge, MA, USA.

Lea, I., 1866. New Unionidae, Melanidae, etc., chiefly of the United States. J. Acad. Nat. Sci. 6, 5-65.

Leach, W.E., 1847. The classification of the British Mollusca. Ann. Mag. Nat. Hist. (Series 1) $20,267-273$.

Lightfoot, J. 1786. A catalogue of the Portland Museum. Skinner, London, UK.

Locard, A., 1889. Catalogue des espèces Française appartenant aux genres Margaritana et Unio connues jusqu'a ce jour. Contribution a la Frauna Malacologique Française, vol. 13, Pitrat aine, Imprimeus, Lyon, France.

Middendorrff, A.T., 1850. Beschreibung einiger Mollusken-arten, nebsteinem Blicke auf der geographischen Character de Land- und Süsswasser-Mollusken Nord-Asiens. Bull. Cl Physico-Mathématique l'Académie Impériale des Sci. Saint-Petersbg. 9, 108-112.

Mörch, O.A.L., 1852-1853. Catalogus conchyliorum quae reliquit D. Alphonso D'Aguirra \& Gadea, Comes de Yoldi, regis daniae cubiculariorum princeps, ordinis dannebrogici in prima classe \& ordinis caroli tertii eques. Hafniae, Typis Ludovici Kleini, Copenhagen, Danmark.

Neave, 2018. Neave Nomenclator zoologicus (accessed 4 January 2018). < http://ubio. org $/ \mathrm{NZ} />$.

Newell, N.D., Boyd, D.W., 1975. Parallel evolution in early trigonacean bivalves. B. Am. Mus. Nat. Hist. 154, 55-162.

Ortmann, A.E., 1911b. A monograph of the najades of Pennsylvania. Parts I and II. Mem. Carnegie Museum 4, 279-347.

Retzius, A.J., 1788. Dissertatio historico-naturalis sistens nova testaceorum genera. Quam præside D.M. Andr. J. Retzio (...) ad publicum examen defert Laurentius Münter Philipsson. Dissertatio Historico-Naturalis, Berling, Lund, Sweden.

Schumacher, C.F., 1817. Essai d'un nouveau système des habitations des vers testacés avec XXII planches. De l'Imprimerie de Mr. le directeur Schultz, Copenhagen, Denmark.

Suchard, M.A., Huelsenbeck, J.P., 2012. MrBayes 3.2: efficient Bayesian phylogenetic inference and model choice across a large model space. Syst. Biol. 61, 539-542. http://dx.doi.org/10.1093/sysbio/sys029.

Swainson, W., 1823. Zoological Illustrations, or Original Figures and Descriptions of New, Rare, or Interesting Animals, Selected Chiefly from the Classes of Ornithology, Entomology, and Conchology, and Arranged on the Principles of Cuvier and Other Modern Zoologists. James Moyes, London, UK.

Vinarski, M.N., Kantor, Y., 2016. Analytical catalogue of fresh and brackish water molluscs of Russia and adjacent countries. A.N. Severtsov Institute of Ecology and Evolution of Russian Academy of Sciences, Moscow, Russia.

Wood, W., 1828. Supplement to the Index Testaceologicus; or a Catalogue of Shells, British and Foreign. Printed by Richard Taylor, Red Lion Coury, Fleet Street, London, UK.

Zatravkin, M.N., Starobogatov, Y.I., 1984. New species of the superfamily Unionoidea (Bivalvia, Unioniformes) from the Soviet Far East. Zool. Zhurnal 63, 1785-1791.

Zilch, A., 1967. Die Typen und Typoide des Natur Museum Senkenberg, 39. Arch. für Molluskenkd. 97, 45-154. 